\title{
TITLE:
}

\section{Phase Evolution of Trirutile Li.FeF for Lithium-Ion Batteries}

\author{
$\operatorname{AUTHOR}(\mathrm{S})$ : \\ Zheng, Yayun; Tawa, Shinya; Hwang, Jinkwang; \\ Orikasa, Yuki; Matsumoto, Kazuhiko; Hagiwara, \\ Rika
}

\section{CITATION:}

Zheng, Yayun ... [et al]. Phase Evolution of Trirutile Li.FeF for Lithium-Ion Batteries. Chemistry of Materials 2021, 33(3): 868-880

\section{ISSUE DATE:}

2021-02

URL:

http://hdl.handle.net/2433/265329

\section{RIGHT:}

This document is the Accepted Manuscript version of a Published Work that appeared in final form in Chemistry of Materials, copyright $\odot$ American Chemical Society after peer review and technical editing by the publisher. To access the final edited and published work see https://doi.org/10.1021/acs.chemmater.0c03544.; The full-text file will be made open to the public on 9 February 2022 in accordance with publisher's 'Terms and Conditions for Self-Archiving.'.; This is not the published version. Please cite only the published version. この論文は出版社版でありません。引用の際には出 版社版をご確認ご利用ください。 


\title{
Phase evolution of trirutile $\mathrm{Li}_{0.5} \mathrm{FeF}_{3}$ for lithium ion batteries
}

\author{
Yayun Zheng, ${ }^{a}$ Shinya Tawa, ${ }^{a}$ Jinkwang Hwang, ${ }^{a}$ Yuki Orikasa, ${ }^{b}$ Kazuhiko Matsumoto, ${ }^{a, *}$ Rika Hagi- \\ wara $^{a}$ \\ ${ }^{a}$ Graduate School of Energy Science, Kyoto University, Yoshida, Sakyo-ku, Kyoto 606-8501, Japan \\ ${ }^{b}$ Department of Applied Chemistry, College of Life Sciences, Ritsumeikan University, 1-1-1 Noji-higashi, Kusatsu, Shiga \\ 525-8577, Japan
}

\begin{abstract}
Extensive studies on the trirutile $\mathrm{Li}_{0.5} \mathrm{FeF}_{3}$ phase have been commissioned in the context of $\mathrm{Li}-\mathrm{Fe}-\mathrm{F}$ system for $\mathrm{Li}$-ion batteries. However, progress in electrochemical and structural studies have been greatly encumbered by the low electrochemical reactivity of this material. In order to advance this class of materials, a comprehensive study into the mechanisms of this phase is necessary. Therefore, herein, we report for the first-time overall reaction mechanisms of the ordered trirutile $\mathrm{Li}_{0.5} \mathrm{FeF}_{3}$ at elevated temperatures of $90{ }^{\circ} \mathrm{C}$ with the aid of a thermally stable ionic liquid electrolyte. The ordered trirutile $\mathrm{Li}_{0.5} \mathrm{FeF}_{3}$ is prepared by highenergy ball milling combined with heat treatment followed by electrochemical tests, X-ray diffraction, and X-ray absorption spectroscopic analyses. Our results reveal that a reversible topotactic $\mathrm{Li}^{+}$extraction/insertion from/into the trirutile structure occurs in a twophase reaction with a minor volume change $\left(1.09 \%\right.$ between $\mathrm{Li}_{0.5} \mathrm{FeF}_{3}$ and $\left.\mathrm{Li}_{0.11} \mathrm{FeF}_{3}\right)$ in the voltage range of 3.2-4.3 V. Extension of the lower cut-off voltage to $2.5 \mathrm{~V}$ results in a conversion reaction to $\mathrm{LiF}$ and rutile $\mathrm{FeF}_{2}$ during discharging. The subsequent charge triggers the formation of the $\mathrm{Li} / \mathrm{Fe}$ disordered trirutile structure at $4.3 \mathrm{~V}$ without showing the reconversion from $\mathrm{LiF}_{\text {and }}$ rutile $\mathrm{FeF} \mathrm{F}_{2}$ to the ordered trirutile $\mathrm{Li}_{0.5} \mathrm{FeF}_{3}$ or $\mathrm{FeF}_{3}$.
\end{abstract}

\section{INTRODUCTION}

The recent proliferation of portable electronics and hybrid electric vehicles have highlighted the compelling need for high energy density and long cycle life among rechargeable battery systems. To sustain the fast-growing energy demand, deployment of lithium-ion batteries (LIBs) has reached unprecedented heights, transcending their conventional counterparts such as nickel-cadmium (Ni-Cd), nickel-metal hydride (Ni-MH), and lead-acid batteries. ${ }^{1-6}$ Even so, the current energy density (500-700 $\mathrm{Wh} \mathrm{kg-active} \mathrm{material}^{-1}$ ) achieved by Li based intercalation compounds such as $\mathrm{LiCoO}_{2}, \mathrm{LiFePO}_{4}$, and $\mathrm{LiNi}_{\mathrm{x}} \mathrm{Co}_{\mathrm{y}} \mathrm{Mn}_{\mathrm{z}} \mathrm{O}_{2}$ is still inadequate, as they inherently have a limited number of available sites in their host lattices. ${ }^{7-9}$ As such, to actualize next-generation LIBs, the pursuit of positive electrode alternatives with higher energy densities is of paramount importance.

In this context, conversion materials that have been found to achieve high reversible capacities through multivalent redox reactions, have gained massive traction as possible positive electrode replacements. ${ }^{10,11}$ Most conversion materials are based on metal fluorides such as $\mathrm{FeF}_{3}, \mathrm{NiF}_{3}, \mathrm{CoF}_{3}, \mathrm{MnF}_{3}$, and $\mathrm{TiF}_{3}$ with particular focus on iron fluorides due to the low cost of iron sources. ${ }^{12-17}$ Extensive studies on $\mathrm{FeF}_{3}$ have reported a high theoretical capacity of $712 \mathrm{mAh} \mathrm{g}^{-1}$ attained from three-electron insertion/extraction and conversion reactions, with several paths for tracking the structural and chemical evolution of $\mathrm{FeF}_{3}$ alongside $\mathrm{Li}^{+}$being explored. ${ }^{10,18-22}$ Early studies on $\mathrm{FeF}_{3}$ proposed a two-step process for the reaction between $\mathrm{Li}^{+}$and $\mathrm{FeF}_{3}$ explicated by the following equations, ${ }^{23,24}$

$$
\begin{aligned}
& \mathrm{Fe}(\mathrm{III}) \mathrm{F}_{3}+\mathrm{Li}^{+}+\mathrm{e}^{-} \rightarrow \mathrm{LiFe}(\mathrm{II}) \mathrm{F}_{3}(4.5-2.5 \mathrm{~V}) \\
& \mathrm{LiFe}(\mathrm{II}) \mathrm{F}_{3}+2 \mathrm{Li}^{+}+2 \mathrm{e}^{-} \rightarrow \mathrm{Fe}(0)+3 \mathrm{LiF}(2.5-1.5 \mathrm{~V})
\end{aligned}
$$

During the first stage (Eq. (1)), the insertion of $0.5 \mathrm{~mol}$ of $\mathrm{Li}^{+}$ results in a two-phase reaction that starts with the formation of an intermediate phase compound, $\mathrm{Li}_{0.5} \mathrm{FeF}_{3}$, followed by a single-phase reaction that forms $\mathrm{LiFeF}_{3}$. The second stage (Eq. (2)) causes a conversion reaction that involves the reduction of $\mathrm{Fe}(\mathrm{II})$ to $\mathrm{Fe}(0)$. As this was the first time that $\mathrm{Li}_{0.5} \mathrm{FeF}_{3}$ was discerned as an intermediate product in the reduction of $\mathrm{FeF}_{3}$ in LIBs, the structures of the two intermediate phases $\mathrm{Li}_{0.5} \mathrm{FeF}_{3}$ and $\mathrm{LiFeF}_{3}$ were not clearly identified. Subsequent first-principle calculations of the Li-Fe-F phase diagram suggested that upon initial insertion into the $\mathrm{FeF}_{3}$, which can be classified as a perovskite structure, $\mathrm{Li}^{+}$occupies the $\mathrm{A}$ site, leading to the formation of $\mathrm{Li}_{0.25} \mathrm{FeF}_{3}$. Additional $\mathrm{Li}^{+}$insertion reactions induce a structural transformation of the perovskite structure to obtain a lithiated trirutile $\mathrm{Li}_{0.5} \mathrm{FeF}_{3}$. However, it was noted that subsequent reactions between $\mathrm{Li}^{+}$and the trirutile $\mathrm{Li}_{0.5} \mathrm{FeF}_{3}$, engendered a conversion reaction that resulted in the formation of $\mathrm{LiF}$ and $\mathrm{Fe}$ instead of the aforementioned experimental path that would entail further insertion of $\mathrm{Li}^{+}$into the trirutile structure to form $\mathrm{Li}_{\mathrm{x}} \mathrm{FeF}_{3}(0.5<\mathrm{x}<1)$ through a single-phase reaction. ${ }^{25}$ To expound on this, Yamakawa et al. identified that the intermediate phase $\mathrm{Li}_{0.5} \mathrm{FeF}_{3}$ was first formed heterogeneously via an insertion reaction, followed by a single-phase intercalation reaction in the range of $0.5<\mathrm{x}<1$ in $\mathrm{Li}_{\mathrm{x}} \mathrm{FeF}_{3}{ }^{26}$ Moreover, through pair distribution function (PDF) analysis, they demonstrated the resemblance between the intermediate product $\mathrm{Li}_{0.5} \mathrm{FeF}_{3}$ and the trirutile structure. More recently, $\mathrm{Li}$ and co-workers combined the results of in-situ synchrotron X-ray absorption spectroscopy (XAS), transmission electron microscopy (TEM), and PDF analysis to indicate the asymmetric reaction pathway of $\mathrm{FeF}_{3}$ with $\mathrm{Li}^{+}$as illustrated by Scheme $1 .{ }^{27}$

Despite the different interpretations derived from the proposed reaction pathways involving $\mathrm{FeF}_{3}$ and $\mathrm{Li}^{+}$, all works

Scheme 1. The discharge and charge reaction pathway of $\mathrm{FeF}_{3}$ with $\mathrm{Li}^{27}$ 


$$
\begin{aligned}
& \text { Rhombohedral } \mathrm{FeF}_{3} \stackrel{+0.25 \mathrm{Li}}{\longrightarrow} \text { Trirutile } \mathrm{Li}_{0.25} \mathrm{FeF}_{3} \stackrel{+0.25 \mathrm{Li}}{\stackrel{+\ldots .2 \mathrm{Li}}{\longrightarrow} \text { Trirutile } \mathrm{Li}_{0.5} \mathrm{FeF}_{3}} \\
& \underset{-0.5 \mathrm{Li}}{\stackrel{+0.5 \mathrm{Li}}{\leftrightarrows}} \text { Rutile } \mathrm{FeF}_{2}+\mathrm{LiF} \underset{-2 \mathrm{Li}}{\stackrel{+2 \mathrm{Li}}{\leftrightarrows}} \mathrm{Fe}+3 \mathrm{LiF}
\end{aligned}
$$

suggest the existence of an intermediate phase $\mathrm{Li}_{x}\left[\mathrm{Fe}^{\mathrm{II}}{ }_{1-}\right.$ ${ }_{x} \mathrm{Fe}^{\mathrm{III}}{ }_{x} \mathrm{~F}_{3}$ before the full reduction of $\mathrm{FeF}_{3}$ to $\mathrm{LiF}$ and Fe. Furthermore, the trirutile $\mathrm{Li}_{0.5} \mathrm{FeF}_{3}$ was calculated to possess a stable crystal structure in the space group of $P 4_{2} / \mathrm{mnm}$ or $P 4_{2} \mathrm{~nm}^{28,29}$ attaining theoretical capacities of 115 and $230 \mathrm{mAh}(\mathrm{g}$ $\left.\mathrm{Li}_{0.5} \mathrm{FeF}_{3}\right)^{-1}$ based on 0.5 -electron and one-electron reactions. As such, understanding the electrochemical behavior of $\mathrm{Li}_{0.5} \mathrm{FeF}_{3}$ as a positive electrode material of LIBs would significantly aid the verification of its reaction pathway in the Li-FeF system. ${ }^{21,27,30}$

Table 1 lists selected reports on the trirutile $\mathrm{Li}_{0.5} \mathrm{FeF}_{3}$ in previous studies. The trirutile structure embodied by $\mathrm{Li}_{0.5}\left[A^{\mathrm{II}}{ }_{0.5} B^{\mathrm{III}}{ }_{0.5}\right] \mathrm{F}_{3}(A, B=$ transition metals $)$ was first envisaged by Viebahn et al, ${ }^{31,32}$ whose work was ensued by direct synthesis of trirutile $\mathrm{Li}_{0.5} \mathrm{FeF}_{3}$ and related $\mathrm{X}$-ray and magnetic structural studies. ${ }^{28,33-35}$ The trirutile structure, also regarded as triple rutile-type structure, has been found to bear structural semblance with related rutile structures especially along the crystallographic $c$-axis on X-ray diffraction (XRD) patterns. ${ }^{29}$ Some reports regarded the trirutile $\mathrm{Li}_{0.5} \mathrm{FeF}_{3}$ as an intermediate phase as described above, ${ }^{25-27}$ however, none of them directly clarified the electrochemical behavior of this phase. In fact, due to the restrictive synthesis conditions of the trirutile $\mathrm{Li}_{0.5} \mathrm{FeF}_{3}$, literature on its electrochemical mechanisms as the positive electrode materials for LIBs remain scarce. Attempts to analyze the electrochemical behavior of $\mathrm{Li}_{0.5} \mathrm{FeF}_{3}$ have been made by Liao et al. via reporting the synthesis of $\mathrm{Li}_{0.5} \mathrm{FeF}_{3}$ with a disordered rutile structure, where the superlattice peak along the $c$-axis disappeared, exposing the formation of a $\mathrm{Li} / \mathrm{Fe}$-disordered rutile structure. Electrochemical tests performed on this disordered $\mathrm{Li}_{0.5} \mathrm{FeF}_{3}$ in LIBs showed a limited capacity in the $\mathrm{LiPF}_{6} / \mathrm{EC}: \mathrm{DEC}$ (1:2 in volume, EC: ethylene carbonate, DEC: diethyl carbonate) organic electrolyte. ${ }^{36,37}$ During the initial discharge and the subsequent initial charge, expansion and contraction of the $a$-axis and the $c$-axis respectively were observed, suggesting the reversible intercalation of $\mathrm{Li}^{+}$within the tunnels of rutile $\mathrm{Li}_{0.5+\mathrm{x}} \mathrm{FeF}_{3}(0<\mathrm{x}<0.3)$ in a single-phase region, which is contrary to the reaction pathway of $\mathrm{FeF}_{3}$ alongside $\mathrm{Li}^{25,27} \mathrm{~A}$ later theoretical study on the phase transition of trirutile $\mathrm{Li}_{0.5} \mathrm{FeF}_{3}$ as well as $\mathrm{Li}^{+}$insertion/extraction in trirutile $\mathrm{Li}_{x} \mathrm{FeF}_{3}$ suggested that the trirutile phase exists in the single phase as a stable structure in the space group of $P 4_{2} / m n m$ as $0.25 \mathrm{Li}^{+}$insertion/extraction into/from the trirutile $\mathrm{Li}_{0.5} \mathrm{FeF}_{3}{ }^{38}$ However, it is worth mentioning that density functional theory (DFT) calculations of the atomic structure and electronic states of $\mathrm{Li}_{x} \mathrm{FeF}_{3}$ revealed that the trirutile $\mathrm{Li}_{0.5} \mathrm{FeF}_{3}$ has the most stable structure in the space group of $P 4_{2} n m$. As $x>0.5, \mathrm{Li}_{x} \mathrm{FeF}_{3}$ is energetically unstable, a conversion reaction occurs in this region. ${ }^{39,40}$ It is noteworthy that, in a technical sense, no experimental report has been presented to illuminate the phase evolution of the ordered trirutile $\mathrm{Li}_{0.5} \mathrm{FeF}_{3}$ as the positive electrode for Li-ion batteries. In this vein, such an attempt would not only mark a great leap towards understanding the electrochemical behavior of $\mathrm{Li}_{0.5} \mathrm{FeF}_{3}$ but also bear great academic significance in the augmentation of this class of materials.

With regards to battery performance, operation at elevated temperatures has been adopted not only as a means to examine the performance of certain electrode materials, but also as a strategy to take advantage of waste heat in large scale applications. ${ }^{41-45}$ However, due to the flammability and volatility of organic electrolytes as well as the instability of solid-electrolyte interphase (SEI) layers, current LIBs are operable in a limited temperature range $\left(<60{ }^{\circ} \mathrm{C}\right)$. On the other hand, ionic liquid (IL) electrolytes have been found to facilitate good battery performance at elevated temperatures, as they are characterized by low volatility, low flammability, wide electrochemical windows, wide liquid temperature ranges, and high thermal, chemical and electrochemical stability. ${ }^{46-53}$ Among them, bis(fluorosulfonyl)amide anion (FSA ${ }^{-}$-based ILs have been widely adopted in rechargeable battery systems owing to their innate high ionic conductivity and ability to form stable solid electrolyte interphases. ${ }^{54-57}$ In particular, $\left[\mathrm{C}_{2} \mathrm{C}_{1}\right.$ im $][\mathrm{FSA}]$ $\left(\mathrm{C}_{2} \mathrm{C}_{1} \mathrm{im}^{+}\right.$: 1-ethyl-3-methylimidazolium) IL exhibits a high ionic conductivity in both ambient and elevated temperatures and is compatible with a wide range of electrode materials. ${ }^{54,55}$ 58-61

Herein, for the first time, we assess the electrochemical performance of the ordered trirutile $\mathrm{Li}_{0.5} \mathrm{FeF}_{3}$ at elevated temperatures of $90{ }^{\circ} \mathrm{C}$ with the aid of the thermally stable Li[FSA]$\left[\mathrm{C}_{2} \mathrm{C}_{1} \mathrm{im}\right][\mathrm{FSA}] \mathrm{IL}$ electrolyte. The ordered trirutile $\mathrm{Li}_{0.5} \mathrm{FeF}_{3}$ is prepared through high-energy ball milling followed by heat treatment at $400{ }^{\circ} \mathrm{C}$. Further, a series of charge-discharge tests and galvanostatic intermittent titration technique (GITT) are performed on the prepared electrode alongside $\mathrm{Li}[\mathrm{FSA}$ $\left[\mathrm{C}_{2} \mathrm{C}_{1} \mathrm{im}\right][\mathrm{FSA}] \mathrm{IL}$. The particle size, morphology of the prepared powder sample, phase evolution, and $\mathrm{Fe}$ oxidation states of the resulting electrode samples are rationalized using the results of scanning electron microscopy (SEM), nitrogen adsorption, (synchrotron) XRD and X-ray absorption fine structure (XAFS) measurements. The inherent performance of $\mathrm{Li}_{0.5} \mathrm{FeF}_{3}$ is discussed in detail in the context of the data obtained.

\section{EXPERIMENTAL}

All nonvolatile materials were handled under an argon atmosphere in a glove box or under a dry air atmosphere in a dry chamber. The starting precursor fluorides, LiF (Sigma Aldrich, Purity $>99.99 \%), \mathrm{FeF}_{2}$ (Sigma Aldrich, Purity > $98 \%$ ), and $\mathrm{FeF}_{3}$ (Sigma Aldrich, Purity $>97 \%$ ) were dried under vacuum at $120{ }^{\circ} \mathrm{C}$. Tetrahydrofuran (THF dehydrated, Wako Pure Chemical Industries, water content $<10$ ppm, stabilizer-free) and Li metal (Sigma-Aldrich, $99.95 \%$ ) were used as purchased. Acetylene black (AB, Wako Pure Chemical Industries, purity > $99.99 \%$ ) and poly(tetrafluoroethylene) (PTFE, Sigma Aldrich, Inc., particle size: ca. $200 \mu \mathrm{m})$ were dried under vacuum at $120^{\circ} \mathrm{C}$ and stored in the glove box. Li[FSA] (Kishida Chemical, water content $<20 \mathrm{ppm}$ ) and $\left[\mathrm{C}_{2} \mathrm{C}_{1} \mathrm{im}\right]$ [FSA] (Kanto Chemical, water content $<20 \mathrm{ppm}$ ) were dried under vacuum at $80{ }^{\circ} \mathrm{C}$. Battery-grade $1 \mathrm{M} \mathrm{LiPF}_{6} / \mathrm{EC}: \mathrm{DMC}$ (1:1 in volume, Kishida Chemical Co. Ltd, EC: ethylene carbonate, DMC: dimethyl carbonate, water content $<30 \mathrm{ppm}$ ) organic electrolyte was used as purchased.

In a typical preparation of $\mathrm{Li}_{0.5} \mathrm{FeF}_{3}, 0.467 \mathrm{~g}$ of $\mathrm{LiF}(0.01800$ $\mathrm{mol}), 1.689 \mathrm{~g}$ of $\mathrm{FeF}_{2}(0.01800 \mathrm{~mol})$, and $2.029 \mathrm{~g}$ of $\mathrm{FeF}_{3}$ $(0.01798 \mathrm{~mol})$ were weighed and loaded in an air-tight bowl with zirconia inner wall under a dry argon atmosphere. The mixture was then ball-milled in a planetary ball mill (Planetary 
Table 1. Summary of major milestones in trirutile $\mathrm{Li}_{0.5} \mathrm{FeF}_{3}$ studies.

\begin{tabular}{|c|c|c|c|c|}
\hline Year & Existent form & Preparation method & Analysis & $\begin{array}{l}\text { Crystallographic and electro- } \\
\text { chemical properties }\end{array}$ \\
\hline $1967^{31}$ & $\begin{array}{c}\text { Trirutile } \mathrm{Li}_{0.5}\left[A^{\mathrm{II}}{ }_{0.5} B^{\mathrm{III}}{ }_{0.5}\right] \mathrm{F}_{3} \\
(A, B=\text { transition metals }) \\
\left(\text { S. G. } P 4_{2} / \text { mnm }\right)\end{array}$ & Solid-state reaction & XRD & $\begin{aligned} & \mathrm{Li}_{0.5 \mathrm{Co} 0.5 \mathrm{Fe}_{0.5} \mathrm{~F}_{3}:} \\
a= & 4.670 \AA, c=9.180 \AA \\
& \mathrm{Li}_{0.5} \mathrm{Ni}_{0.5} \mathrm{Fe}_{0.5} \mathrm{~F}_{3}: \\
a= & 4.630 \AA, c=9.150 \AA\end{aligned}$ \\
\hline $1968^{33}$ & $\begin{array}{l}\text { Trirutile } \mathrm{Li}_{0.5} \mathrm{FeF}_{3} \\
\text { (S. G. } P 42 / m n m)\end{array}$ & Solid-state reaction & XRD & $a=4.673 \AA, c=9.290 \AA$ \\
\hline $1969^{32}$ & $\begin{array}{c}\text { Trirutile } \mathrm{Li} 0.5\left[A^{\mathrm{II}}{ }_{0.5} B^{\mathrm{III}} 0.5\right] \mathrm{F}_{3} \\
(A, B=\text { transition metals }) \\
\left(\text { S. G. } P 4_{2} / \text { mnm }\right)\end{array}$ & Solid-state reaction & XRD & $\begin{aligned} & \mathrm{Li}_{0.5} \mathrm{Co} 0.5 \mathrm{Fe}_{0.5} \mathrm{~F}_{3}: \\
a= & 4.665 \AA, c=9.159 \AA \\
& \mathrm{Li}_{0.5} \mathrm{Ni}_{0.5} \mathrm{Fe}_{0.5} \mathrm{~F}_{3}: \\
a= & 4.648 \AA, c=9.128 \AA \\
& \mathrm{Li}_{0.5} \mathrm{Zn}_{0.5} \mathrm{Fe}_{0.5} \mathrm{~F}_{3}: \\
a= & 4.671 \AA, c=9.154 \AA\end{aligned}$ \\
\hline $1971^{34}$ & Trirutile $\mathrm{Li}_{0.5} \mathrm{FeF}_{3}$ & Solid-state reaction & $\begin{array}{l}\text { Mössbauer spectros- } \\
\text { copy }\end{array}$ & None \\
\hline $1972^{28}$ & $\begin{array}{l}\text { Trirutile } \mathrm{Li}_{0.5} \mathrm{FeF}_{3} \\
\left(\text { S. G. } P 4_{2} / m n m\right)\end{array}$ & Solid-state reaction & $\begin{array}{l}\text { Neutron diffraction, } \\
\text { Magnetic structure }\end{array}$ & $a=4.673 \AA, c=9.290 \AA$ \\
\hline $1972^{35}$ & $\begin{array}{l}\text { Trirutile } \mathrm{Li}_{0.5} \mathrm{FeF}_{3} \\
\left.\text { (S. G. } P 4_{2} / m n m\right)\end{array}$ & Solid-state reaction & $\begin{array}{l}\text { Neutron diffraction, } \\
\text { Magnetic structure }\end{array}$ & $a=4.673 \AA, c=9.290 \AA$ \\
\hline $1988^{29}$ & $\begin{array}{l}\text { Trirutile } \mathrm{Li}_{0.5} \mathrm{FeF}_{3} \\
\left.\quad \text { (S. G. } P 4_{2} n m\right)\end{array}$ & Hydrothermal synthesis & Single-crystal XRD & $a=4.679 \AA, c=9.324 \AA$ \\
\hline $2008^{25}$ & $\begin{array}{l}\text { Trirutile } \mathrm{Li}_{0.5 \mathrm{FeF}} \mathrm{F}_{3} \\
\text { (S. G. } P 4_{2} / \mathrm{mnm} \text { ) }\end{array}$ & $\begin{array}{l}\text { Calculated intermediate } \\
\text { phase upon } \mathrm{Li}^{+} \text {insertion } \\
\text { into } \mathrm{FeF}_{3}\end{array}$ & $\begin{array}{l}\text { DFT calculation for the } \\
\text { Li-Fe-F system }\end{array}$ & $a=4.756 \AA, c=9.339 \AA$ \\
\hline $2009^{26}$ & $\begin{array}{l}\text { Trirutile } \mathrm{Li}_{0.5} \mathrm{FeF}_{3} \\
\left.\text { (S. G. } P 4_{2} / \mathrm{mnm}\right)\end{array}$ & $\begin{array}{l}\text { Intermediate phase upon } \\
\mathrm{Li}^{+} \text {insert into } \mathrm{FeF}_{3}\end{array}$ & $\begin{array}{l}\text { XRD, PDF analysis and } \\
\text { solid-state NMR }\end{array}$ & $\begin{array}{l}\text { The intermediate phase appears } \\
\text { during discharge of a FeF} 3 \text { elec- } \\
\text { trode at } 127 \mathrm{mAh} \mathrm{g}^{-1}\end{array}$ \\
\hline $2010^{36}$ & $\begin{array}{l}\text { Disordered rutile } \mathrm{Li}_{0.5} \mathrm{FeF}_{3} \\
\text { and } \mathrm{Li}_{0.6} \mathrm{FeF}_{3.1} \\
\left.\text { (S. G. } \mathrm{P}_{2} / \mathrm{mnm}\right)\end{array}$ & Solid-state reaction & XRD, In-situ XRD & $\begin{array}{c}\text { Initial discharge capacity of } 102 \\
\mathrm{mAh} \mathrm{g}^{-1} \text { at } 2.5 \mathrm{~V} \text { and } 126 \mathrm{mAh} \\
\mathrm{g}^{-1} \text { at } 2.0 \mathrm{~V}, 81 \% \text { capacity re- } \\
\text { tention after } 17 \text { cycles between } \\
2.5-4.0 \mathrm{~V} \text { and } 62 \% \text { capacity } \\
\text { retention after } 14 \text { cycles be- } \\
\text { tween } 2.0-4.5 \mathrm{~V}\end{array}$ \\
\hline $2010^{37}$ & $\begin{array}{l}\text { Disordered rutile } \mathrm{Li}_{0.6} \mathrm{FeF}_{3.1} \\
\quad \text { (S. G. } P 4_{2} / \mathrm{mnm} \text { ) }\end{array}$ & Solid-state reaction & $\begin{array}{l}\text { XRD, Mössbauer spec- } \\
\text { tra }\end{array}$ & $a=4.717 \AA, c=3.127 \AA$ \\
\hline $2013^{38}$ & $\begin{array}{l}\text { Trirutile } \mathrm{Li}_{0.5} \mathrm{FeF}_{3} \\
\left.\text { (S. G. } P 4_{2} / \mathrm{mnm}\right)\end{array}$ & Calculation & DFT calculation & $a=4.726 \AA, c=9.222 \AA$ \\
\hline $2016^{27}$ & Trirutile $\mathrm{Li}_{0.5} \mathrm{FeF}_{3}$ & $\begin{array}{l}\text { Intermediate phase upon } \\
\mathrm{Li}^{+} \text {insert into } \mathrm{FeF}_{3}\end{array}$ & $\begin{array}{l}\text { In-situ XAS, DFT cal- } \\
\text { culation }\end{array}$ & $\begin{array}{c}\text { The intermediate phases appear } \\
\text { during discharge and charge of } \\
\text { a } \mathrm{FeF}_{3} \text { electrode at } 1 / 6 \mathrm{C}\end{array}$ \\
\hline $2017^{39}$ & $\begin{array}{l}\text { Trirutile } \mathrm{Li}_{0.5} \mathrm{FeF}_{3} \\
\left.\quad \text { (S. G. } P 4_{2} n m\right)\end{array}$ & Calculation & DFT calculation & $a=4.666 \AA, c=9.253 \AA$ \\
\hline $2019^{40}$ & $\begin{array}{l}\text { Trirutile } \mathrm{Li}_{0.5} \mathrm{FeF}_{3} \\
\quad \text { (S. G. } P 4_{2 n m} \text { ) }\end{array}$ & $\begin{array}{l}\text { Calculated intermediate } \\
\text { phase upon } \mathrm{Li}^{+} \text {insert into } \\
\mathrm{FeF}_{3}\end{array}$ & $\begin{array}{l}\text { DFT calculation, Den- } \\
\text { sity of states (DOS) } \\
\text { analysis, X-ray absorp- } \\
\text { tion near edge structure } \\
\text { (XANES) analysis }\end{array}$ & $a=4.725 \AA, c=9.383 \AA$ \\
\hline
\end{tabular}


Micro Mill PULVERISETTE 7 premium line, Fritsch) at 600 $\mathrm{rpm}$ for $6 \mathrm{~h}$ with zirconia balls ( $3 \mathrm{~mm}$ in diameter). After the ball milling process, the bowl was opened in the glove box, and the sample was transferred into a nickel boat. The nickel boat was thereafter sealed in a stainless steel pipe with a valve in the glove box and the entire pipe was transferred to the vacuum line. Heat treatment was then performed on the sample at $400{ }^{\circ} \mathrm{C}$ for $17 \mathrm{~h}$ under vacuum. A target sample of $\mathrm{Li}_{0.5} \mathrm{FeF}_{3}$ (approximately $3.7 \mathrm{~g}$ ) was recovered from the nickel boat in the glove box.

The XRD patterns of $\mathrm{Li}_{0.5} \mathrm{FeF}_{3}$ at different synthetic stages were recorded in the Bragg-Brentano geometry using a Rigaku MiniFlex diffractometer with $\mathrm{Ni}$-filtered $\mathrm{Cu}-\mathrm{K} \alpha$ radiation (30 $\mathrm{kV}$ and $10 \mathrm{~mA}$ ) and D/tex Ultra250 Si-strip high-speed detector. Structural parameters were refined with the Rietveld refinement by curve-fitting using the GSAS and FullProf data analysis software. ${ }^{62,63}$ The crystal structure was visualized by the VESTA program. ${ }^{64}$ The morphology of the prepared $\mathrm{Li}_{0.5} \mathrm{FeF}_{3}$ powder was identified via field-emission SEM (Hitachi SU-8020). Elemental distribution over the $\mathrm{Li}_{0.5} \mathrm{FeF}_{3}$ electrode was obtained by energy dispersion X-ray spectroscopic (EDX) mapping (Horiba EMAXEvolution). Nitrogen adsorption analysis was performed using a Tristar II 3020 equipment (Shimadzu Corp.) to evaluate the Brunauer-Emmett-Teller (BET) surface area of the $\mathrm{Li}_{0.5} \mathrm{FeF}_{3}$ sample. The $\mathrm{Li}$ and $\mathrm{Fe}$ contents in $\mathrm{Li}_{0.5} \mathrm{FeF}_{3}$ were determined after dissolution with sulfuric, nitric and perchloric acids by atomic absorption spectrometry (AAS, Hitachi Z-2300) and inductively coupled plasma - atomic emission spectrometry (ICP-AES, Hitachi PS3520VDD II), respectively. Synchrotron XRD patterns of $\mathrm{Li}_{0.5} \mathrm{FeF}_{3}$ at different charge-discharge stages were recorded in the BL5S2 of Aichi Synchrotron Radiation Center equipped with a PILATUS 100K two-dimensional detector with a wavelength of $0.9997 \AA$. The electrode powders washed with THF and vacuum-dried at room temperature were sealed in Lindeman glass capillaries. For XAFS measurements, the electrode powders after charging and discharging $(\sim 6.7 \mathrm{mg})$ were thoroughly mixed with boron nitride $(250 \mathrm{mg})$ and then molded into pellets. All the XAFS data were measured using the BL-3 at Synchrotron Radiation Center, Ritsumeikan University, at room temperature. The Fe $K$-edge spectra were obtained in a transmission mode.

The $\mathrm{Li}_{0.5} \mathrm{FeF}_{3} / \mathrm{AB}$ composite (75:25 in weight) was prepared by dry ball milling at $600 \mathrm{rpm}$ for one hour in the same synthesis process as the $\mathrm{Li}_{0.5} \mathrm{FeF}_{3}$. The powdered $\mathrm{Li}_{0.5} \mathrm{FeF}_{3} / \mathrm{AB}$ composite was recovered in the glove box and heated at $300{ }^{\circ} \mathrm{C}$ for $6 \mathrm{~h}$ under vacuum. The PTFE binder was thoroughly mixed with the $\mathrm{Li}_{0.5} \mathrm{FeF}_{3} / \mathrm{AB}$ composite $\left(\mathrm{Li}_{0.5} \mathrm{FeF}_{3} / \mathrm{AB}: \mathrm{PTFE}=95: 5\right.$ in weight) using an agate mortar and a pestle to form a homogeneous electrode sheet. The sheet was pressed onto a fresh $\mathrm{Al}$ mesh (13 $\mathrm{mm}$ in diameter) to prepare the test electrode with a loading mass of $\sim 3 \mathrm{mg} \mathrm{cm}^{-2}$.

Coin cells (2032-type) were assembled in the Ar-filled glove box with the $\mathrm{Li}_{0.5} \mathrm{FeF}_{3}$ working electrode, the $\mathrm{Li}[\mathrm{FSA}]-$ $\left[\mathrm{C}_{2} \mathrm{C}_{1} \mathrm{im}\right][\mathrm{FSA}]$ (30:70 in mol) ionic liquid (IL) electrolyte, and $\mathrm{Li}$ metal disk counter electrode fixed on stainless steel (SUS316L) plate current collector. The glass microfiber separator (Whatman, GF/A; $16 \mathrm{~mm}$ in diameter and $260 \mu \mathrm{m}$ in thickness) was immersed in the IL electrolyte under vacuum at $90{ }^{\circ} \mathrm{C}$ for $12 \mathrm{~h}$ prior to the cell assembling.

All the electrochemical data were obtained by an HJ-SD8 charge-discharge system (Hokuto Denko). The charge-discharge curves and cycling performance of the working electrode were measured by galvanostatic charge-discharge tests. In this study, the rate of $1 \mathrm{C}$ corresponds to $115 \mathrm{mAh}\left(\mathrm{g}^{-} \mathrm{Li}_{0.5} \mathrm{FeF}_{3}\right)$ ${ }^{1}$, and the capacity of the positive electrode is shown as a value per weight (in grams) of $\mathrm{Li}_{0.5} \mathrm{FeF}_{3}$. Galvanostatic intermittent titration techniques (GITT) was employed to assess the overpotentials by repeatedly monitoring the voltage relaxation in the open-circuit state immediately after charging or discharging to a certain voltage.

\section{RESULTS AND DISCUSSION}

To understand the structure of the ball-milled mixture, XRD patterns were taken before $\left(\mathrm{B}-\mathrm{Li}_{0.5} \mathrm{FeF}_{3}\right)$ and after heat treatment at $400{ }^{\circ} \mathrm{C}\left(\mathrm{BH}-\mathrm{Li}_{0.5} \mathrm{FeF}_{3}\right)$ as shown in Figure $\mathrm{S} 1$ (Supporting Information). In the case of $\mathrm{B}-\mathrm{Li}_{0.5} \mathrm{FeF}_{3}$ (Figure $\mathrm{S} 1$ (a)), several broad peaks are discerned. However, the strongest peak, which can be assigned to residual $\mathrm{FeF}_{3}$ (space group: $R-3 \mathrm{c}^{24,25}$ ), appears around $23.94^{\circ}$ suggesting that the ball milling process alone does not facilitate a complete reaction. The other peaks observed are assignable to the rutile-type $\mathrm{Li}_{0.5} \mathrm{FeF}_{3}$ where $\mathrm{Li}$ and $\mathrm{Fe}$ are disordered. It is noted that the two characteristic superlattice peaks attributed to the trirutile $\mathrm{Li}_{0.5} \mathrm{FeF}_{3}$ are not detected at 19.26 and $21.46^{\circ}$ before the heat treatment. Upon heat treatment at $400{ }^{\circ} \mathrm{C}$ (Figure S1 (b)), the diffraction peaks of $\mathrm{BH}$ $\mathrm{Li}_{0.5} \mathrm{FeF}_{3}$ become significantly sharper while the peak assignable to $\mathrm{FeF}_{3}$ is observed to disappear. Rietveld refinement employed for further analysis of the $\mathrm{BH}-\mathrm{Li}_{0.5} \mathrm{FeF}_{3}$ indicated that the XRD pattern is well-fitted within the parameters of the trirutile $\mathrm{Li}_{0.5} \mathrm{FeF}_{3}$ structure in the $P 4_{2} / \mathrm{mnm}$ space group $\left(R_{\mathrm{p}}=\right.$ $1.30 \%, R_{\text {wp }}=2.04 \%$ ) as highlighted by the fitting results (Figure 1 (a)) and summarized in Table 2 . The $\mathrm{Li}_{0.5} \mathrm{FeF}_{3}$ trirutile structure is characterized by edge-sharing among $\mathrm{Li}^{+} \mathrm{F}_{6}, \mathrm{Fe}^{2+} \mathrm{F}_{6}$, and $\mathrm{Fe}^{3+} \mathrm{F}_{6}$ octahedra, with a distinct $\mathrm{Li}^{+}-\mathrm{Fe}^{2+}-\mathrm{Fe}^{3+}$ cationic ordering along the $c$-axis (Figure 1 (b)). This creates tunnels that facilitate $\mathrm{Li}^{+}$extraction/insertion from/into the host lattice. ${ }^{29,31}$ 35, 65 Also, the minor peaks of an impurity $\mathrm{FeF}_{2}$ phase, seen in the diffraction patterns (Figure S1 (b) and Figure 1 (a)) are verified as $2.53 \mathrm{wt} \%$ by the Rietveld analysis.

To enhance the electronic conductivity of the composite electrode, the crystalline $\mathrm{Li}_{0.5} \mathrm{FeF}_{3}$ sample was ball-milled with $\mathrm{AB}$ in the weight ratio of $\mathrm{Li}_{0.5} \mathrm{FeF}_{3}: \mathrm{AB}=75: 25 .^{66} \mathrm{XRD}$ patterns of the repeatedly ball-milled sample with $\mathrm{AB}$ were obtained before $\left(\mathrm{RB}-\mathrm{Li}_{0.5} \mathrm{FeF}_{3}\right)$ and after heat treatment at $300{ }^{\circ} \mathrm{C}(\mathrm{RBH}-$ $\mathrm{Li}_{0.5} \mathrm{FeF}_{3}$ ) as shown in Figures S1 (c) and (d). Upon ball milling with $\mathrm{AB}$ (Figure $\mathrm{S} 1$ (c)), the diffraction peaks of $\mathrm{RB}-\mathrm{Li}_{0.5} \mathrm{FeF}_{3}$ appear to be broadened and weakened featuring two rather dim characteristic peaks of the trirutile structure around $20^{\circ}$. However, these characteristic peaks appear again after the heat treatment of the $\mathrm{RB}-\mathrm{Li}_{0.5} \mathrm{FeF}_{3}$ sample, suggesting the recovery of the $\mathrm{Li}$ and $\mathrm{Fe}$ ordering (Figure $\mathrm{S} 1$ (d), $\mathrm{RBH}-\mathrm{Li}_{0.5} \mathrm{FeF}_{3}$ ). A comparison between the XRD patterns of $\mathrm{BH}_{-}-\mathrm{Li}_{0.5} \mathrm{FeF}_{3}$ and $\mathrm{RBH}$ $\mathrm{Li}_{0.5} \mathrm{FeF}_{3}$ (Figures $\mathrm{S} 1$ (b) and (d)) indicates that except for the broadening of the diffraction peaks caused by a decrease in crystallite size, the introduction of $\mathrm{AB}$ creates no significant changes in the structure and impurity phases (see Figure S2 for the SEM images). This suggests that the mechanical force generated by the high-energy ball milling process is not strong enough to break the Fe-F bonds. Although partial reduction of $\mathrm{Fe}(\mathrm{III})$ at $300{ }^{\circ} \mathrm{C}$ under vacuum may occur under the existence of $\mathrm{AB}$ in this study (cf. the heat treatment of $\mathrm{FeF}_{3}$ with carbon materials under an $\mathrm{Ar}$ flow) ${ }^{67}$ the amount of $\mathrm{FeF}_{2}$ produced by the reduction is considered to be very limited according to the 
(a)

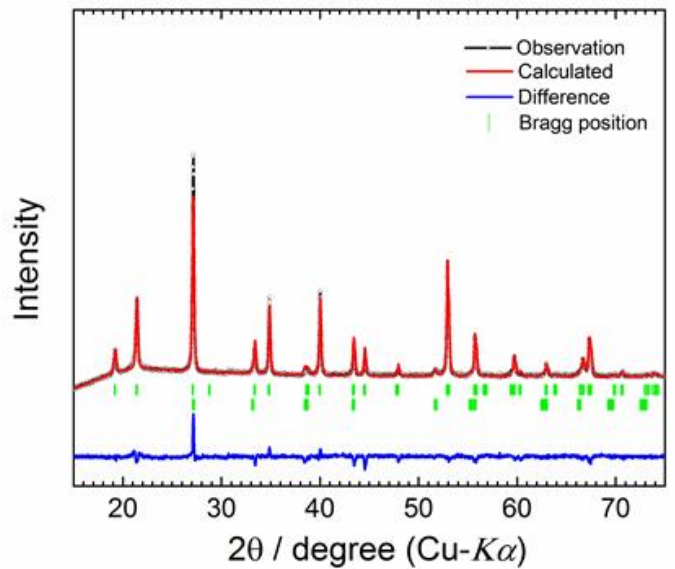

(b)

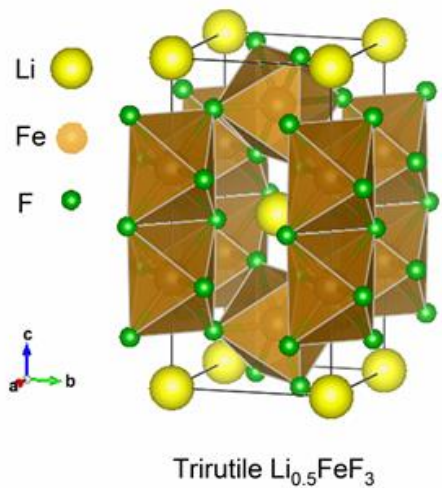

Figure 1. (a) $\mathrm{XRD}$ patterns and Rietveld refinement results of the trirutile $\mathrm{Li}_{0.5} \mathrm{FeF}_{3}$ sample prepared by the heat treatment of the ballmilled mixture of $\mathrm{LiF}, \mathrm{FeF}_{2}$, and $\mathrm{FeF}_{3}$ at $400{ }^{\circ} \mathrm{C}$ for $17 \mathrm{~h}$ (Figure $\mathrm{S} 1$ (b), $\mathrm{BH}-\mathrm{Li}_{0.5} \mathrm{FeF}_{3}$ ) and (b) the refined crystal structure. See Table 2 for the crystallographic data.

Table 2. Crystallographic parameters of $\mathrm{BH}-\mathrm{Li} \mathbf{0}_{.5} \mathrm{FeF}_{3}$ obtained from Rietveld refinement.

Refinement results for BH-Li ${ }_{0.5} \mathrm{FeF}_{3}$ (S.G. $P 4_{2} / m n m$ ) $R_{\mathrm{p}}=1.30 \%, R_{\mathrm{wp}}=2.04 \%$

\begin{tabular}{|c|c|c|c|c|c|c|}
\hline \multicolumn{2}{|c|}{$a=4.6799(6) \AA$} & \multicolumn{3}{|c|}{$c=9.3161(1) \AA$} & \multicolumn{2}{|c|}{$V=204.041(7) \AA^{3}$} \\
\hline Atom & Wyckoff symbol & $x$ & $y$ & $z$ & $B_{\text {iso }} / \AA^{2}$ & Occup. \\
\hline $\mathrm{Li}$ & $2 a$ & 0 & 0 & 0 & 0.5 & 1 \\
\hline $\mathrm{Fe}$ & $4 e$ & 0 & 0 & $0.3333(5)$ & 0.5 & 1 \\
\hline $\mathrm{F} 1$ & $4 f$ & $0.2916(3)$ & $0.2916(3)$ & 0 & 0.5 & 1 \\
\hline $\mathrm{F} 2$ & $8 j$ & $0.3031(2)$ & $0.3031(2)$ & $0.3360(1)$ & 0.5 & 1 \\
\hline
\end{tabular}

subsequent Rietveld refinement of the $\mathrm{RBH}-\mathrm{Li}_{0.5} \mathrm{FeF}_{3}$ electrode (see below).

SEM measurements were additionally taken to examine the morphological properties of the pristine $\mathrm{BH}-\mathrm{Li}_{0.5} \mathrm{FeF}_{3}$ and $\mathrm{RBH}-\mathrm{Li}_{0.5} \mathrm{FeF}_{3}$ samples as shown in Figure $\mathrm{S} 2$. Results indicate that both samples are composed of micro-sized secondary particles which are agglomerates of nanoparticles (Figures S2 (a) and (b)). The pristine $\mathrm{BH}-\mathrm{Li}_{0.5} \mathrm{FeF}_{3}$ has larger particles (above $100 \mathrm{~nm}$ ) than $\mathrm{RBH}-\mathrm{Li}_{0.5} \mathrm{FeF}_{3}$ (above $50 \mathrm{~nm}$ ), indicating that the ball milling process further ground the $\mathrm{Li}_{0.5} \mathrm{FeF}_{3}$ particles and that nano-sized $\mathrm{AB}$ particles were introduced. The homogeneous distribution of $\mathrm{Fe}$ and $\mathrm{F}$ atoms in micrometer order is also confirmed by EDX analysis (Figures S2 (a) and (b)). The increase in BET surface area from $3.1 \mathrm{~m}^{2} \mathrm{~g}^{-1}\left(\mathrm{BH}_{-}-\mathrm{Li}_{0.5} \mathrm{FeF}_{3}\right)$ to 88 $\mathrm{m}^{2} \mathrm{~g}^{-1}\left(\mathrm{RBH}-\mathrm{Li}_{0.5} \mathrm{FeF}_{3}\right)$ also indicates the decrease in $\mathrm{Li}_{0.5} \mathrm{FeF}_{3}$ particle size, but the contribution of $\mathrm{AB}$ surface area seems to be more significant ( $\mathrm{AB}$ only: $53 \mathrm{~m}^{2} \mathrm{~g}^{-1}$ before ball milling and $327 \mathrm{~m}^{2} \mathrm{~g}^{-1}$ after ball milling, see Figure S3 and Table S1 with additional comments). The $\mathrm{Li}$ and $\mathrm{Fe}$ contents in the $\mathrm{BH}-$ $\mathrm{Li}_{0.5} \mathrm{FeF}_{3}$ were determined by the AAS and ICP-AES analyzers. The $\mathrm{BH}-\mathrm{Li}_{0.5} \mathrm{FeF}_{3}$ sample has $\mathrm{Li}$ and $\mathrm{Fe}$ contents of 3.0 and 47.5 $\mathrm{wt} \%$, respectively, which are close to the theoretical values of 3.0 and $48.0 \mathrm{wt} \%$ e.

To investigate the electrochemical behavior of the RBH$\mathrm{Li}_{0.5} \mathrm{FeF}_{3}$ electrode, galvanostatic charge-discharge tests were performed on a half-cell configuration comprising a Li metal counter electrode and $\mathrm{Li}[\mathrm{FSA}]-\left[\mathrm{C}_{2} \mathrm{C}_{1} \mathrm{im}\right][\mathrm{FSA}](30: 70 \mathrm{in} \mathrm{mol})$
IL electrolyte. Two different cut-off voltage ranges of 3.2-4.3 $\mathrm{V}$ and $2.5-4.3 \mathrm{~V}$ were set at a rate of $0.2 \mathrm{C}\left(\sim 20 \mathrm{~mA} \mathrm{~g}^{-1}\right)$ and a temperature of $90{ }^{\circ} \mathrm{C}$ as highlighted by the charge-discharge curves and the corresponding differential capacity versus potential $(\mathrm{d} Q / \mathrm{d} V)$ plots shown in Figure 2. For the 3.2-4.3 V voltage range (Figure 2 (a)), an initial charge capacity of $122 \mathrm{mAh} \mathrm{g}^{-1}$ characterized by a plateau around $4.0 \mathrm{~V}$ is obtained. The three initial cycles exhibit superposing discharge curves that plateau around $3.9 \mathrm{~V}$, attaining a reversible capacity of $89.8 \mathrm{mAh} \mathrm{g}^{-1}$. As will be explained hereinafter, the plateau corresponds to the extraction/insertion of 0.5 -electron $\mathrm{Li}^{+}$from/into the host trirutile lattice. ${ }^{36}$ The ratio of the discharge capacity to the theoretical capacity $\left(115 \mathrm{mAh} \mathrm{g}^{-1}\right.$ for $0.5 \mathrm{Li}$ per $\left.\mathrm{Li}_{0.5} \mathrm{FeF}_{3}\right)$ indicates that $0.39 \mathrm{Li}^{+}$extraction/insertion is achieved during the charge-discharge process. The coulombic efficiency of the three initial cycles increases as the cycles progress from $73.5 \%$ in the first cycle to $87.8 \%$ in the third cycle. The irreversible capacity observed is ascribed to the side reactions to which the oxidative decomposition of the electrolyte mostly contributes. ${ }^{68}$ The corresponding $\mathrm{d} Q / \mathrm{d} V$ curves of the first three cycles are shown in Figure 2 (b). There is only a pair of redox peaks in the cut-off voltage of 3.2-4.3 V, which is attributed to $\mathrm{Li}^{+}$extraction/insertion from/into the host trirutile lattice occurs at $4.01 \mathrm{~V}$ and 3.95 $\mathrm{V}$, respectively. No significant changes are noted in the positions of the redox couple throughout the first three cycles, demonstrating the high reversibility of the charge-discharge process in the $3.2-4.3 \mathrm{~V}$ voltage range. 

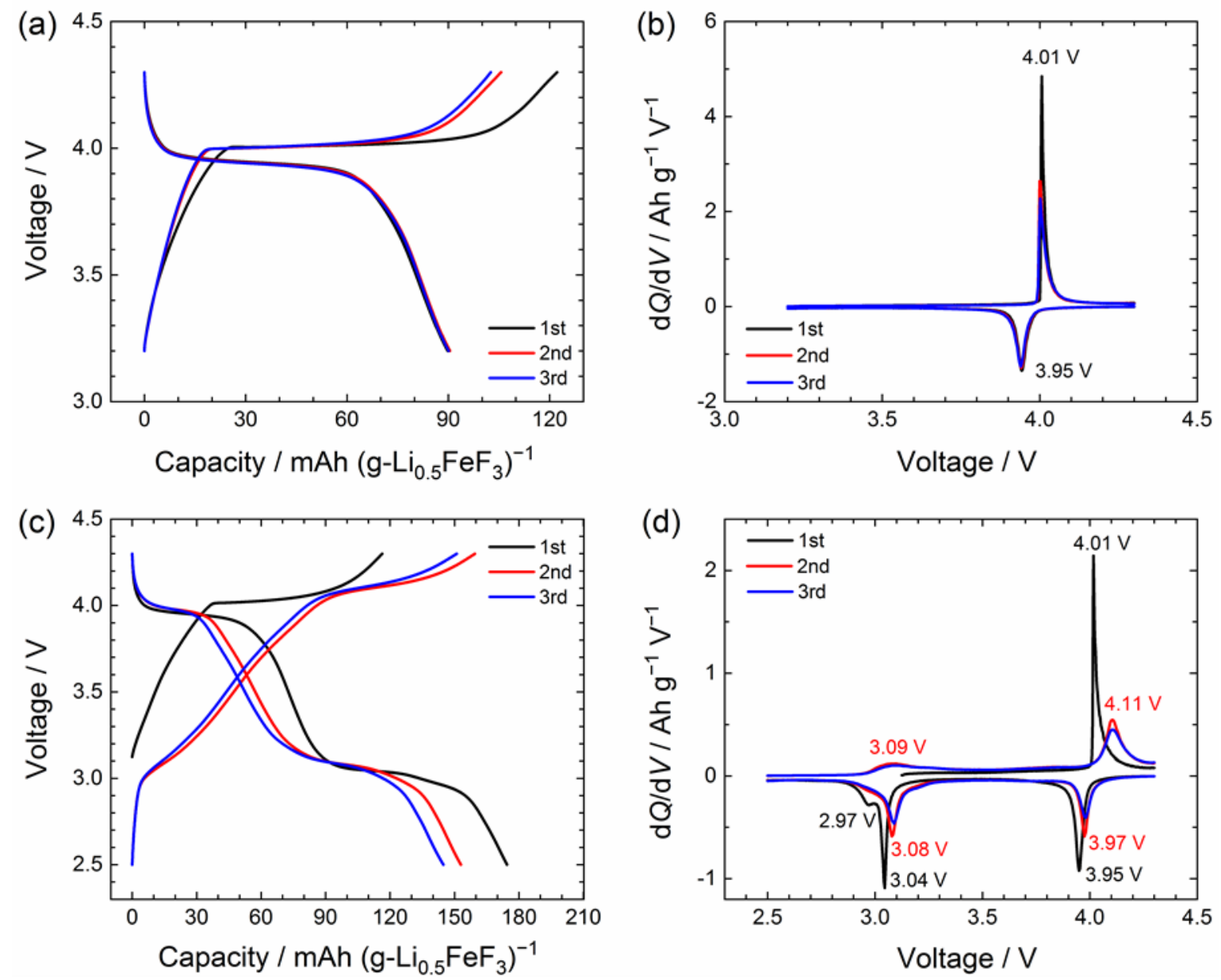

Figure 2. Charge-discharge curves of the $\mathrm{RBH}-\mathrm{Li}_{0.5} \mathrm{FeF}_{3}$ electrode evaluated using ionic liquid $\mathrm{Li}[\mathrm{FSA}]-\left[\mathrm{C}_{2} \mathrm{C}_{1} \mathrm{im}\right][\mathrm{FSA}]$ (30:70 in mol) at $90{ }^{\circ} \mathrm{C}$. (a) The first three cycles between 3.2-4.3 V and (b) the corresponding $\mathrm{d} Q / \mathrm{d} V$ plots of the charge-discharge curves in (a) during the initial three cycles. (c) The first three cycles between 2.5-4.3 V and (d) the corresponding $\mathrm{d} Q / \mathrm{d} V$ plots of the charge-discharge curves in (c) during the initial three cycles.

To explore the electrochemical properties of $\mathrm{Li}_{0.5} \mathrm{FeF}_{3}$ at a lower potential, charge-discharge profiles were obtained in the 2.5-4.3 V voltage range (Figure 2 (c)). During the initial cycle, a discharge capacity of $174.5 \mathrm{mAh} \mathrm{g}^{-1}$ marked by a plateau around $3.0 \mathrm{~V}$ is obtained. As elucidated by previous reports on the reaction mechanism of $\mathrm{FeF}_{3}$ and confirmed by synchrotron XRD results hereafter, the plateau appearing around $3.0 \mathrm{~V}$ during the discharge process is thought to originate from the conversion reaction of $\mathrm{Li}_{0.5} \mathrm{FeF}_{3}$ to $\mathrm{LiF}$ and $\mathrm{FeF}_{2}$ (see below for further discussion). ${ }^{27}$ The capacity of the $3.2-2.5 \mathrm{~V}$ region is 91.1 $\mathrm{mAh} \mathrm{g}$, equivalent to $0.40 \mathrm{Li}^{+}$reaction. In the second charging process, a change in the curve gradient is observed from $3.0 \mathrm{~V}$ onwards with a short plateau appearing around $4.1 \mathrm{~V}$. The specific voltages where these plateaus are located are further confirmed by the corresponding $\mathrm{d} Q / \mathrm{d} V$ plots (Figure $2(\mathrm{~d})$ ). When the lower cut-off voltage is reduced to $2.5 \mathrm{~V}$, significant changes in both the peak intensity and position of the two redox couples are observed during the first two cycles. However, almost no changes are observed as the cycle progress from the 2 nd to the 3 rd cycle. The reaction mechanisms represented by these peaks will be later expounded in the context of GITT and synchrotron XRD results. To discern the effects of temperature on electrode behavior, galvanostatic charge-discharge tests in the 3.2-4.3 $\mathrm{V}$ and $2.5-4.3 \mathrm{~V}$ voltage ranges were performed on a $\mathrm{Li}[\mathrm{FSA}]-\left[\mathrm{C}_{2} \mathrm{C}_{1} \mathrm{im}\right][\mathrm{FSA}] \mathrm{IL}$ electrolyte and $1 \mathrm{M}$ $\mathrm{LiPF}_{6} / \mathrm{EC}: \mathrm{DMC}$ organic electrolyte at $25{ }^{\circ} \mathrm{C}$ (Figure S4, Supporting Information). In the IL electrolyte (Figures S4 (a) and (b)), RBH-Li $\mathrm{Li}_{0.5} \mathrm{FeF}_{3}$ exhibits poor electrochemical activity with no distinct plateaus appearing in both voltage ranges. Similar electrochemical activities are observed in the organic electrolyte as shown in Figures S4 (c) and (d). These results suggest that the ionic conductivities of $\mathrm{Li}_{0.5} \mathrm{FeF}_{3}$ and charge transfer at the interphase thwart its activation toward $\mathrm{Li}^{+}$extraction/insertion in these conditions, which is limited by the large secondary particles. It should be noted that the $\mathrm{Li}_{0.5} \mathrm{FeF}_{3} / \mathrm{AB}$ composite electrode without ball-milling exhibits a very limited electrochemical activity in the IL electrolyte even at $90{ }^{\circ} \mathrm{C}$ (Figure S5). However, the $\mathrm{RB}-\mathrm{Li}_{0.5} \mathrm{FeF}_{3}$ treated only by ball-milling (Figure S6) shows high charge-discharge capacities in the IL electrolyte at $90{ }^{\circ} \mathrm{C}$, and moderate capacities even at room temperature in both IL electrolyte and organic electrolyte. These results indicate that the activity of $\mathrm{Li}_{0.5} \mathrm{FeF}_{3}$ is not just brought out by the operation at elevated temperature, but also by the formation of a carbon composite with ball-milling for appropriate electronic conduction. 


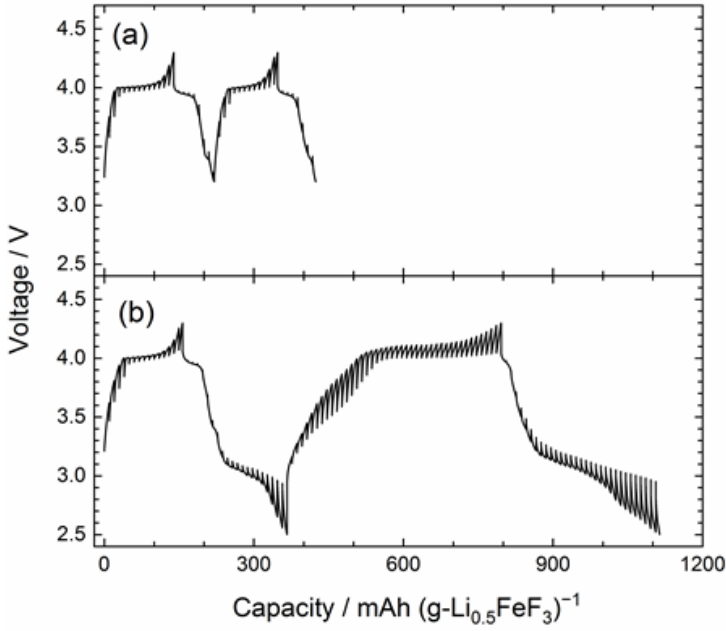

Figure 3. The GITT curves of the $\mathrm{RBH}-\mathrm{Li}_{0.5} \mathrm{FeF}_{3}$ electrode in the voltage ranges of (a) $3.2-4.3 \mathrm{~V}$ and (b) $2.5-4.3 \mathrm{~V}$ at $90{ }^{\circ} \mathrm{C}$. The GITT conditions were conducted via a stepwise polarization at 50 $\mathrm{mA} \mathrm{g}^{-1}$ for $1 \mathrm{~h}$ and thereafter left at an open-circuit state for $2.5 \mathrm{~h}$.

The cycling performance of $\mathrm{RBH}-\mathrm{Li}_{0.5} \mathrm{FeF}_{3}$ for the two voltage ranges $(3.2-4.3 \mathrm{~V}$ and $2.5-4.3 \mathrm{~V})$ was examined using the Li[FSA]-[C $\left.{ }_{2} \mathrm{C}_{1} \mathrm{im}\right][\mathrm{FSA}] \mathrm{IL}$ electrolyte at $90{ }^{\circ} \mathrm{C}$, and their resulting discharge capacity and coulombic efficiency as a function of cycle number are shown in Figures S7 and S8. In the 3.2-4.3 V voltage range (Figures S7 (a) and (b)), the discharge capacity decreases from 89.8 to $85.7 \mathrm{mAh} \mathrm{g}^{-1}$ over the first 20 cycles, delivering a capacity retention of $95.4 \%$. This demonstrates that the ordered $\mathrm{Li}_{0.5} \mathrm{FeF}_{3}$ trirutile structure can be reversibly delithated/lithiated in the IL electrolyte at $90{ }^{\circ} \mathrm{C}$. The coulombic efficiency increases as the cycle progress, reaching more than $90 \%$ after 10 cycles. However, it is seen to fluctuate around $90 \%$ after 25 cycles. This can be ascribed to the occurrence of the aforementioned side reactions. ${ }^{68}$ Although coulombic efficiency was improved by the combination of $\mathrm{CC}$ (constant current) charge and CCCV (constant current-constant voltage) discharge modes in the voltage range of $3.2-4.3 \mathrm{~V}$ (Figure S9), the capacity retention $81.7 \%$ at the 20th cycle is lower than $95.4 \%$ obtained for the CC charge and CC discharge modes (Figure S7 in Supporting Information).

In the case of 2.5-4.3 V voltage range (Figures S8 (a) and (b)), the discharge capacity is seen to fade during the first five cycles, thereafter flattening to become almost constant. A relatively low capacity retention of $81.5 \%$ is achieved at the 20th cycle $\left(142.3 \mathrm{mAh} \mathrm{g}^{-1}\right)$. The initial coulombic efficiency is noted to be over $100 \%$ because the amount of $\mathrm{Li}^{+}$insertion exceeds the $0.5 \mathrm{Li}^{+}$extraction from $\mathrm{Li}_{0.5} \mathrm{FeF}_{3}$ in this cut-off voltage. Upon subsequent cycling, the coulombic efficiency gradually decreases from $95.9 \%$ in the second cycle but later increases with further cycling, resulting in $96.1 \%$ at the 20th cycle. Although the cycle performance of the trirutile $\mathrm{Li}_{0.5} \mathrm{FeF}_{3}$ in the IL electrolyte at $90{ }^{\circ} \mathrm{C}$ is not superior to other reported state-ofthe-art positive electrode materials that include some iron fluorides, ${ }^{69-72}$ this cycle performance suggests that this electrode material is suitable for clarifying the reaction mechanism of the trirutile $\mathrm{Li}_{0.5} \mathrm{FeF}_{3}$.

To gain insight into the reaction mechanisms of the ordered trirutile $\mathrm{Li}_{0.5} \mathrm{FeF}_{3}$, GITT measurements were performed through repeated monitoring of the voltage relaxation during the opencircuit state after charging or discharging to certain cell voltages.
Figure 3 shows the GITT curves of $\mathrm{RBH}-\mathrm{Li}_{0.5} \mathrm{FeF}_{3}$ electrode during the first two cycles in the 3.2-4.3 V and 2.5-4.3 V voltage ranges at $90{ }^{\circ} \mathrm{C}$. During the first charge in the cut-off voltage of 3.2-4.3 V (Figure 3 (a)), the open-circuit voltage after relaxation gradually increases, indicating the occurrence of a single-phase reaction. A capacity of $26.3 \mathrm{mAh} \mathrm{g}^{-1}$ is eventually attained representing the extraction of $0.11 \mathrm{Li}^{+}$from the trirutile $\mathrm{Li}_{0.5} \mathrm{FeF}_{3}$. Upon reaching $4.0 \mathrm{~V}$, the relaxation potential remains virtually unchanged, which is an indication of a two-phase reaction occurring between the trirutile phase and another phase. At the end of the initial charging process, a gradual increase in the open-circuit voltage after relaxation is observed, suggesting the occurrence of another single-phase reaction. During the subsequent discharge process, a plateau corresponding to the twophase reaction can be observed around $3.9 \mathrm{~V}$, indicating the same reaction path for the delithiation and lithiation processes. The second cycle of the GITT test, essentially yields the same charge-discharge curve as the first cycle, demonstrating the same reaction mechanisms and the high reversibility of delithiation/lithiation processes within the trirutile structure in the cutoff voltage of $3.2-4.3 \mathrm{~V}$.

Drastic changes on the voltage profiles are seen to occur when the lower cut-off voltage is reduced (Figure 3 (b)). When the initial discharge is extended to $2.5 \mathrm{~V}$, further lithiation beyond $\mathrm{Li}_{0.5} \mathrm{FeF}_{3}$ is perceived to occur, as manifested by the two sloping regions in the galvanostatic charge-discharge test in Figure 2 (c). The overpotential in the corresponding GITT curve increases as the lithiation continues. During the second charging process, a sloping curve is observed between $3.2-3.9 \mathrm{~V}$, followed by a constant open-circuit voltage of $3.9 \mathrm{~V}$. This is a manifestation that the phase evolution is different from the one in the initial discharging. The absence of a plateau around 3.0 $\mathrm{V}$, previously observed in the first discharge, indicates the poor recovery from the phases formed when trirutile $\mathrm{Li}_{0.5} \mathrm{FeF}_{3}$ is discharged to $2.5 \mathrm{~V}$ to trirutile $\mathrm{Li}_{0.5} \mathrm{FeF}_{3}$. Moreover, the second discharge process is marked by a limited capacity for the plateau region at $3.9 \mathrm{~V}$ and a large overpotential below $3.2 \mathrm{~V}$. Combining the voltage profiles from the galvanostatic charge-discharge and GITT tests (Figures 2 and 3) reveals that extending discharge process to $2.5 \mathrm{~V}$ causes a poor reversible reaction which results in incomplete recovery of the trirutile $\mathrm{Li}_{0.5} \mathrm{FeF}_{3}$ after undergoing the electrochemical reaction in this voltage region.

To verify the phase transformation and reaction mechanism during the initial charge-discharge and second charge processes, synchrotron XRD and XAFS analyses were carried out on the trirutile $\mathrm{Li}_{0.5} \mathrm{FeF}_{3}$ as summarized by Figure 4 . The states analyzed by XRD and XAFS are highlighted by potential-time profile (Figure 4 (a)), alongside XRD patterns of the RBH$\mathrm{Li}_{0.5} \mathrm{FeF}_{3}$ electrode in the different charge/discharge states (Figure $4(\mathrm{~b}))$. The peak at $2 \theta=11.68^{\circ}$, which is allocated to the PTFE binder, ${ }^{73,74}$ appears throughout the entire delithiation and lithiation paths. As can be seen in the crystallographic data and refinement results obtained through Rietveld refinement (Table 3 and Figure S10 (a)), the diffraction peaks of the pristine electrode (Pattern 1) are mostly indexed to the trirutile $\mathrm{Li}_{0.5} \mathrm{FeF}_{3}$ in the space group of $P 4_{2} / \mathrm{mnm}$, which corroborates with the data of the as-prepared material (Table 2) and confirms that the crystal structure of $\mathrm{Li}_{0.5} \mathrm{FeF}_{3}$ (Pattern 1) is not influenced by $\mathrm{AB}$ and PTFE in the formation of the composite. A slight amount of $\mathrm{FeF}_{2}(3.63 \mathrm{wt} \%)$ is observed as confirmed in the as-prepared sample (Figure 1 (a) and Figure S1 (b)). After the initial charge 
(c)

(a)

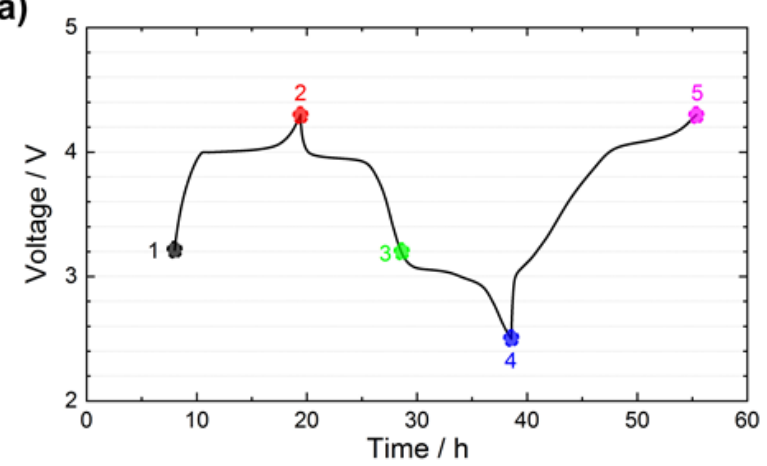

(b)

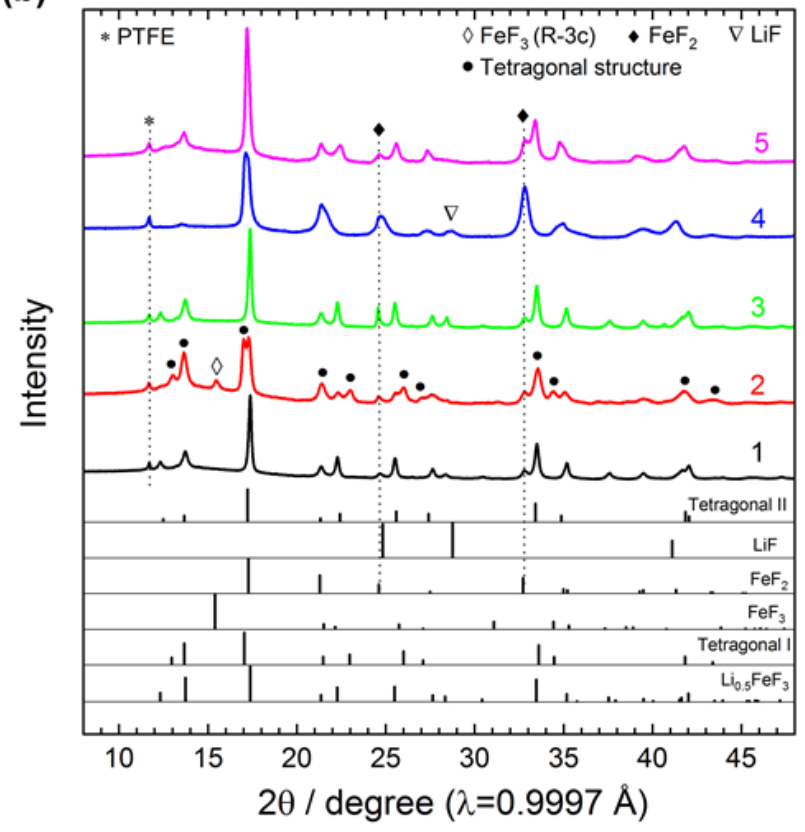

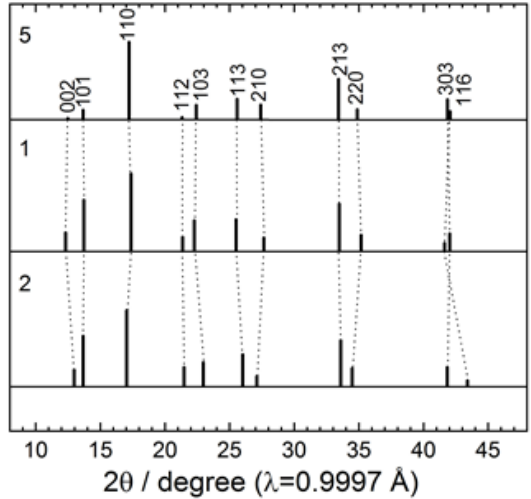

(d)

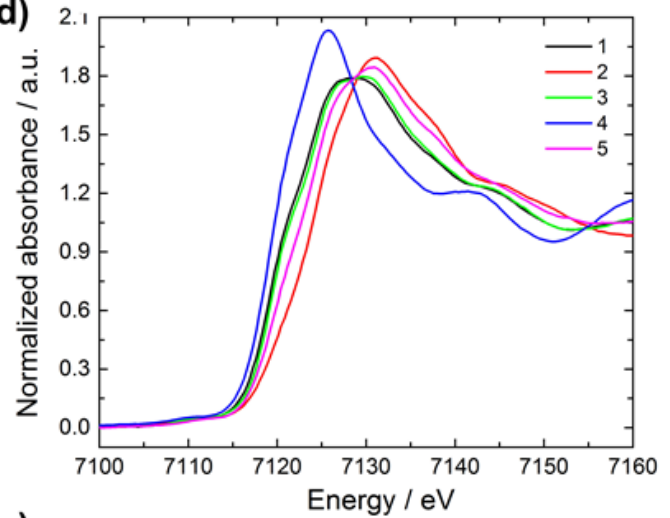

(e)

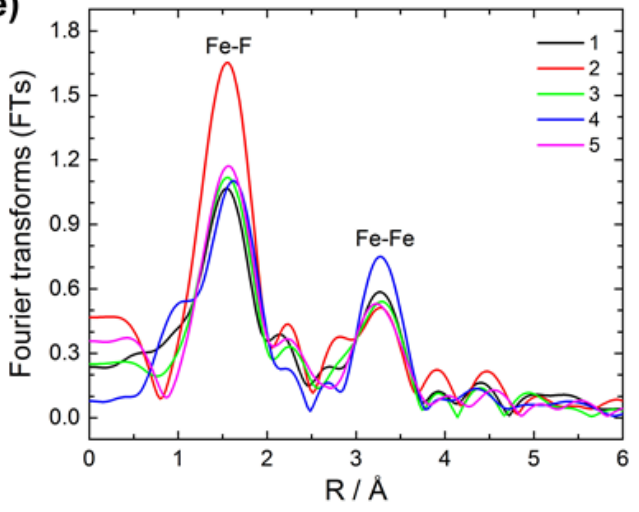

Figure 4. Synchrotron XRD and XAFS results for the $\mathrm{RBH}-\mathrm{Li}_{0.5} \mathrm{FeF}_{3}$ electrode. (a) Charge and discharge voltage profiles taken at a current density equivalent to $0.1 \mathrm{C}\left(1 \mathrm{C}=115 \mathrm{mAh} \mathrm{g}^{-1}\right)$ at $90{ }^{\circ} \mathrm{C}$ : (1) Pristine state, (2) initial charge to $4.3 \mathrm{~V}$, (3) half discharge to $3.2 \mathrm{~V}$, (4) full discharge to $2.5 \mathrm{~V}$, and (5) second charge to $4.3 \mathrm{~V}$. (b) Synchrotron XRD patterns $(\lambda=0.9997 \AA)$ of the charged and discharged samples. (c) Simulated XRD peak positions of the trirutile $\mathrm{Li}_{0.5} \mathrm{FeF}_{3}$ (Pattern 1), Tetragonal I phase obtained after the initial charge (Pattern 2), and Tetragonal II phase obtained after the second charge (Pattern 5). The original XRD patterns are shown in (b). (d) Fe $K$-edge XANES spectra and (e) corresponding Fourier transforms of the EXAFS oscillations.

(Pattern 2), some residual peaks of the trirutile $\mathrm{Li}_{0.5} \mathrm{FeF}_{3}$ are still observed in their original positions, conforming with the insufficient practical capacity (78\% based on the theoretical capacity) indicated by the electrochemical data (Figure 2 (a)). The new peak appearing at $15.45^{\circ}$ is designated as the strongest diffraction peak of $\mathrm{FeF}_{3}$ (012 diffraction) belonging to the space group of $R-3 \mathrm{c}$. This shows that during the initial charge process, $\mathrm{FeF}_{3}$ is generated from the residual $\mathrm{FeF}_{2}$ and $\mathrm{LiF}$ left-over from the preparation process of trirutile $\mathrm{Li}_{0.5} \mathrm{FeF}_{3}$. This side reaction is consistent with the results drawn from the phase evolution of $\mathrm{LiF} / \mathrm{FeF}_{2}$ in previous works. ${ }^{68,75}$ In addition, shifts in several diffraction peaks belonging to trirutile $\mathrm{Li}_{0.5} \mathrm{FeF}_{3}$ are observed. Some diffraction peaks are seen to shift to lower angles while others appear to shift to higher angles, revealing the formation of a new tetragonal phase (Tetragonal I). Further analysis by the Rietveld refinement (Table 3 and Figure S10 (b)) elaborates that these diffraction peaks can be indexed as a tetragonal phase with larger $a$ and smaller $c$ lattice parameters than those of the original trirutile $\mathrm{Li}_{0.5} \mathrm{FeF}_{3}$, suggesting that delithiation results in isotropic lattice expansion to the $a$ - and $b$-axes and shrinkage along the $c$-axis. The unit cell volume after delithiation is 201.650(3) $\AA^{3}$, which corresponds to a $1.09 \%$ decrease from the initial unit cell volume of the trirutile structure. This volume change is smaller than that of typical positive electrode materials during the process of $\mathrm{Li}^{+}$extraction, such as $\mathrm{LiCoO}_{2}(\sim 2.0 \%$, $\mathrm{SOC}=0.5),{ }^{76,77}$ spinel-type $\mathrm{LiMn}_{2} \mathrm{O}_{4}(\sim 3.2 \%, \mathrm{SOC}=0.5)^{78,79}$ and olivine-type $\mathrm{LiFePO}_{4}(\sim 4.6 \% \text {, SOC }=0.5)^{80,81}$, although 
Table 3. Crystallographic parameters of the trirutile $\mathrm{Li}_{0.5} \mathrm{FeF}_{3}$, Tetragonal I, discharge state and Tetragonal II appearing during the charge-discharge process of the $\mathrm{RBH}-\mathrm{Li}_{0.5} \mathrm{FeF}_{3}$ electrode obtained by Rietveld refinement.

\begin{tabular}{|c|c|c|c|c|c|c|}
\hline \multicolumn{7}{|c|}{ Refinement results for trirutile $\mathrm{Li}_{0.5} \mathrm{FeF}_{3}(\text { Pattern } 1)^{a}\left(\right.$ S.G. $\left.P 4_{2} / m n m\right) R_{\mathrm{p}}=2.27 \%, R_{\mathrm{wp}}=3.65 \%$} \\
\hline \multicolumn{2}{|c|}{$a=4.6798(1) \AA$} & \multicolumn{3}{|c|}{$c=9.3095(4) \AA$} & \multicolumn{2}{|c|}{$V=203.879(1) \AA^{3}$} \\
\hline Atom & Wyckoff symbol & $x$ & $y$ & $z$ & Biso $/ \AA^{2}$ & Occup. \\
\hline $\mathrm{Li}$ & $2 a$ & 0 & 0 & 0 & 0.5 & 1 \\
\hline $\mathrm{Fe}$ & $4 e$ & 0 & 0 & $0.3321(2)$ & 0.5 & 1 \\
\hline $\mathrm{F} 1$ & $4 f$ & $0.2894(6)$ & $0.2894(6)$ & 0 & 0.5 & 1 \\
\hline $\mathrm{F} 2$ & $8 j$ & $0.3098(4)$ & $0.3098(4)$ & $0.3424(4)$ & 0.5 & 1 \\
\hline \multicolumn{7}{|c|}{ Refinement results for Tetragonal I (Pattern 2$)^{b}\left(\right.$ S.G. $\left.P 4_{2} / m n m\right) R_{\mathrm{p}}=2.61 \%, R_{\mathrm{wp}}=3.70 \%$} \\
\hline \multicolumn{2}{|c|}{$a=4.7718(3) \AA$} & \multicolumn{3}{|c|}{$c=8.8557(1) \AA$} & \multicolumn{2}{|c|}{$V=201.650(3) \AA^{3}$} \\
\hline Atom & Wyckoff symbol & $x$ & $y$ & $z$ & Biso / $\AA^{2}$ & Occup. \\
\hline $\mathrm{Fe}$ & $4 e$ & 0 & 0 & $0.3277(3)$ & 0.5 & 1 \\
\hline $\mathrm{F} 1$ & $4 f$ & $0.3038(1)$ & $0.3038(1)$ & 0 & 0.5 & 1 \\
\hline F2 & $8 j$ & $0.2974(7)$ & $0.2974(7)$ & $0.3382(8)$ & 0.5 & 1 \\
\hline \multicolumn{7}{|c|}{ Refinement results for discharge state $(\text { Pattern } 4)^{c}\left(\right.$ S.G. $\left.P 4_{2} / m n m\right) R_{\mathrm{p}}=2.64 \%, R_{\mathrm{wp}}=4.21 \%$} \\
\hline \multicolumn{2}{|c|}{$a=4.7029(2) \AA$} & \multicolumn{3}{|c|}{$c=3.2586(3) \AA$} & \multicolumn{2}{|c|}{$V=72.074(8) \AA^{3}$} \\
\hline Atom & Wyckoff symbol & $x$ & $y$ & $z$ & $B$ iso / $\AA^{2}$ & Occup. \\
\hline $\mathrm{Fe}$ & $2 a$ & 0 & 0 & 0 & 0.5 & 1 \\
\hline $\mathrm{F}$ & $4 f$ & $0.3065(4)$ & $0.3065(4)$ & 0 & 0.5 & 1 \\
\hline \multicolumn{7}{|c|}{ Refinement results for Tetragonal II (Pattern 5) ${ }^{d}$ (S.G. $\left.P 4_{2} / m n m\right) R_{\mathrm{p}}=2.76 \%, R_{\mathrm{wp}}=4.01 \%$} \\
\hline \multicolumn{2}{|c|}{$a=4.7189(2) \AA$} & \multicolumn{3}{|c|}{$c=9.1972(8) \AA$} & \multicolumn{2}{|c|}{$V=204.799(2) \AA^{3}$} \\
\hline Atom & Wyckoff symbol & $x$ & $y$ & $z$ & $B$ iso / $\AA^{2}$ & Occup. \\
\hline $\mathrm{Fe} 1$ & $2 a$ & 0 & 0 & 0 & 0.5 & $0.374(4)$ \\
\hline $\mathrm{Fe} 2$ & $4 e$ & 0 & 0 & $0.3375(4)$ & 0.5 & $0.834(5)$ \\
\hline $\mathrm{F} 1$ & $4 f$ & $0.3265(1)$ & $0.3265(1)$ & 0 & 0.5 & 1 \\
\hline $\mathrm{F} 2$ & $8 j$ & $0.3278(7)$ & $0.3278(7)$ & $0.3471(9)$ & 0.5 & 1 \\
\hline
\end{tabular}

${ }^{a} \mathrm{FeF}_{2}\left(P 4_{2} / m n m\right)$ is considered to be an impurity phase. ${ }^{b}$ Trirutile $\mathrm{Li}_{0.5} \mathrm{FeF}_{3}\left(P 4_{2} / m n m\right), \mathrm{FeF}_{2}\left(P 4_{2} / m n m\right)$, and $\mathrm{FeF} 3(R-3 c)$ are considered to be impurity phases. $\mathrm{Li}$ is not included in the analysis. ${ }^{c}$ Trirutile $\mathrm{Li}_{0.5} \mathrm{FeF}_{3}\left(P 4_{2} / m n m\right)$ is considered to be an impurity phase. ${ }^{d} \mathrm{FeF} 2(P 42 / m n m)$ is considered to be an impurity phase. $\mathrm{Li}$ is not included in the analysis.

the amount of $\mathrm{Li}^{+}$extracted is limited in the present case. After discharging to $3.2 \mathrm{~V}$ (Pattern 3), the diffraction peaks shift back to their original positions, suggesting that the trirutile structure is recovered at $3.2 \mathrm{~V}$ by inserting $\sim 0.39 \mathrm{Li}^{+}$into the original sites. The disappearance of the $\mathrm{FeF}_{3}$ diffraction peak after discharging to $3.2 \mathrm{~V}$ indicates that lithiation of the $\mathrm{FeF}_{3}$ phase results in the trirutile $\mathrm{Li}_{0.5} \mathrm{FeF}_{3}$ or $\mathrm{FeF}_{2}$ alongside $\mathrm{LiF}$. This insertion reaction has been widely investigated among the $\mathrm{FeF}_{3}$ electrodes ${ }^{26,27}$ and the $\mathrm{LiF} / \mathrm{FeF}_{2}$ nanocomposites. ${ }^{68}$ Compared to the disordered rutile-type $\mathrm{Li}_{0.5} \mathrm{FeF}_{3}$ reported in a previous work, ${ }^{36}$ this study provides more detailed structural information on the phase transition in the cut-off voltage range of 3.2-4.3 V.

Further discharge to $2.5 \mathrm{~V}$ (Pattern 4) results in the decrease of the trirutile $\mathrm{Li}_{0.5} \mathrm{FeF}_{3}$ phase according to Rietveld refinement (8.48 wt\%), and the increase of the rutile $\mathrm{FeF}_{2}$ and $\mathrm{LiF}$ to the main phases (Table 3 and Figure S10 (c)). This observation indicates that the conversion reaction at $2.5 \mathrm{~V}$ from the trirutile $\mathrm{Li}_{0.5} \mathrm{FeF}_{3}$ phase to $\mathrm{FeF}_{2}$ and $\mathrm{LiF}$ occurs after the disintegration of trirutile phase. Similar behavior is recognized in the previous report on the Li-Fe-F system, regardless of the starting phase.${ }^{27}$ However, the conversion reaction is not complete and the trirutile $\mathrm{Li}_{0.5} \mathrm{FeF}_{3}$ phase exists as an impurity phase due to the incomplete conversion reaction. After the second charge to 4.3 V (Pattern 5), the XRD pattern observed can be indexed as a tetragonal structure alongside the residual peaks belonging to $\mathrm{FeF}_{2}$. These peaks (denoted as Tetragonal II) show slight shifts compared to those of the initial trirutile structure (Pattern 1) and Tetragonal I after the initial charge (Pattern 2), suggesting the trirutile structure is no longer recovered by delithiation from the two-phase mixture of rutile $\mathrm{FeF}_{2}$ and $\mathrm{LiF}$. Further verification by Rietveld refinement (Figure S10 (d)) identified Tetragonal II as the disordered trirutile structure of $\mathrm{Li} / \mathrm{Fe}$. The corresponding crystallographic data (Table 3 ) indicates that second delithiation results in a $0.83 \%$ increase in the $a$ lattice parameter and a $1.20 \%$ decrease in the $c$ lattice parameter, causing a $0.45 \%$ overall increase in volume from the initial trirutile $\mathrm{Li}_{0.5} \mathrm{FeF}_{3}$. No peaks of $\mathrm{FeF}_{3}$ are observed after the second charge, suggesting that $\mathrm{FeF}_{3}$ is not formed from the $\mathrm{FeF}_{2}$ and $\mathrm{LiF}$, as will be hereafter confirmed by XAFS data. Figure 4 (c) shows the schematic drawing of the changes in XRD patterns from trirutile $\mathrm{Li}_{0.5} \mathrm{FeF}_{3}$ 


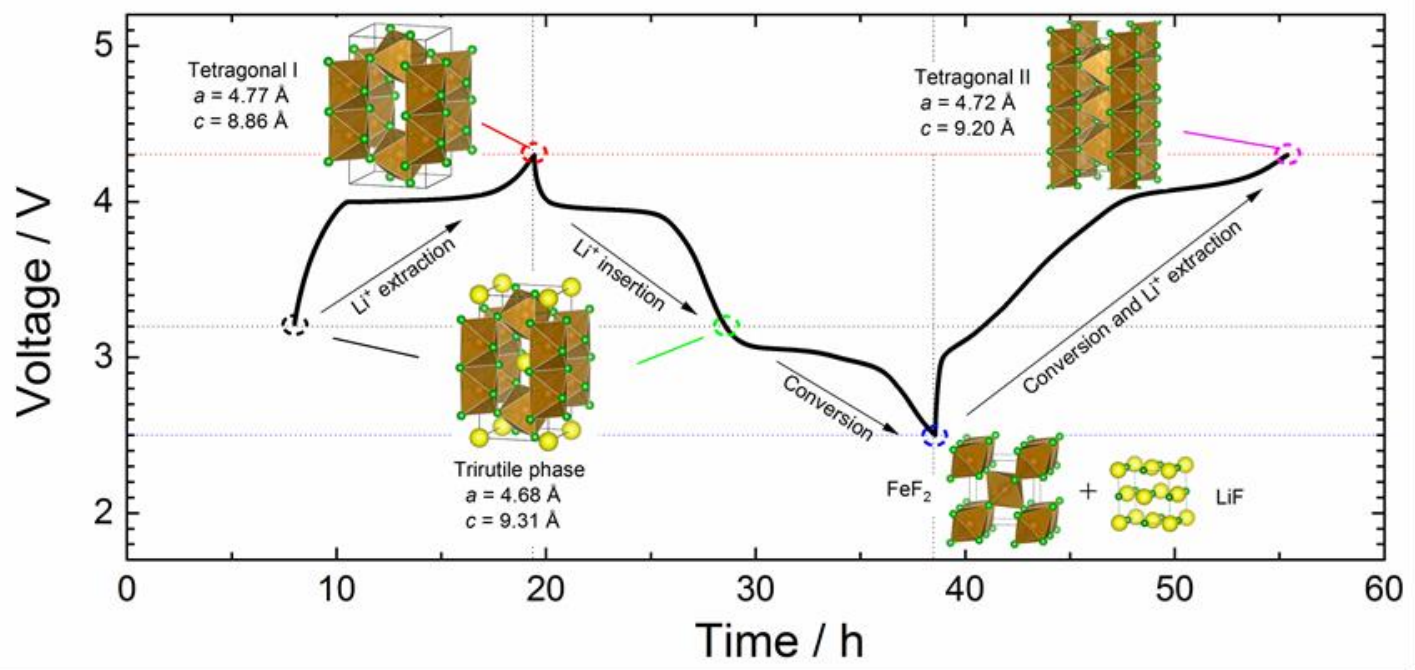

Figure 5. Schematic illustration of the reaction pathway for the RBH-Li $0.5 \mathrm{FeF}_{3}$ electrode during the charge-discharge process. Tetragonal I phase has a delithiated trirutile structure, whereas Tetragonal II phase has a Li-Fe disordered trirutile structure. See Supporting Information for further conversion reaction below $2.5 \mathrm{~V}$ (Figure S11).

to Tetragonal I and Tetragonal II (Patterns 1, 2 and 5), where each peak is identified according to the crystallographic data by Rietveld refinement. The position shifts and intensity changes of the diffraction peaks as a result of delithiation can be visually tracked from the initial trirutile structure to the resulting Tetragonal I and II structures.

The Fe $K$-edge XAFS spectra provide the information on the oxidation state and local structure around $\mathrm{Fe}$ atoms that occurs during the charge-discharge test of the $\mathrm{RBH}-\mathrm{Li}_{0.5} \mathrm{FeF}_{3}$ electrode. Figure $4(\mathrm{~d})$ demonstrates Fe $K$-edge XANES spectra of the $\mathrm{RBH}-\mathrm{Li}_{0.5} \mathrm{FeF}_{3}$ electrode at different states of charge and discharge. The absorption edge evolution indicates the variation of Fe oxidation states. ${ }^{68,82-84}$ After the initial charging process to $4.3 \mathrm{~V}\left(x \sim 0.39\right.$ in $\left.\mathrm{Li}_{0.5-\mathrm{x}} \mathrm{FeF}_{3}\right)$, the main Fe $K$-edge absorption edge exhibits a high-energy shift to the edge of $\mathrm{Fe}^{3+}$-containing reference compounds (Spectra 1 and 2), ${ }^{68,85}$ suggesting the oxidation from $\mathrm{Fe}^{2+}$ to $\mathrm{Fe}^{3+}$. After the subsequent discharge to 3.2 $\mathrm{V}$ (Spectrum 3 ), the Fe $K$-edge position returns to the original position. The spectra overlap between the pristine state (Spectrum 1) and the state after discharge to $3.2 \mathrm{~V}$ (Spectrum 3 ) indicates the reversibility of the topotactic $\mathrm{Li}^{+}$extraction/insertion from/into the trirutile structure. By further discharging to $2.5 \mathrm{~V}$ (Spectrum 4), the shift of Fe $K$-edge to a further lower energy corresponding to the $\mathrm{Fe}^{2+}$ edge position is observed, ${ }^{27,85,86}$ evidencing the reduction to $\mathrm{Fe}^{2+}$ during this discharge process. After the second charge to $4.3 \mathrm{~V}$ (Spectrum 5), the XANES spectrum does not overlap with the one obtained after the initial charge (Spectrum 2), suggesting less $\mathrm{Li}^{+}$extraction from the host lattice of trirutile structure.

To investigate the local structure of $\mathrm{Fe}$ atoms in the RBH$\mathrm{Li}_{0.5} \mathrm{FeF}_{3}$ electrode under different charging and discharging states, Fe K-edge extended X-ray absorption fine-structure spectroscopy (EXAFS) analysis was employed as shown by the Fourier transform (FT) spectra in Figure 4 (e). The FT EXAFS spectra are significantly altered by the initial charging (Spectra 1 and 2) and returns to the original form after discharging to 3.2 $\mathrm{V}$ (Spectrum 3 ). The first peak centered around $1.56 \AA$ corresponds to the contribution of the Fe-F first-neighboring shell, whereas the second peak appearing around $3.28 \AA$ represents the contribution of the Fe-Fe first-neighboring shell. ${ }^{68}$ The primary Fe-F distance is enlarged to $1.63 \AA$ after the discharging process to $2.5 \mathrm{~V}$ (Spectrum 4), which agrees with the reduction from $\mathrm{Fe}^{3+}$ to $\mathrm{Fe}^{2+}$ as suggested by the aforementioned XANES analysis. The misalignment of the curves after recharging to 4.3 $\mathrm{V}$ (Spectrum 5) and the state of first charge (Spectrum 2) is another evidence that the second delithiation has a higher overpotential compared to the first one.

Figure 5 illustrates the entire phase evolution of the $\mathrm{RBH}-$ $\mathrm{Li}_{0.5} \mathrm{FeF}_{3}$ electrode during the charge-discharge process in IL electrolyte at $90{ }^{\circ} \mathrm{C}$. In the voltage range of $3.2-4.3 \mathrm{~V}$, the topotactic $\mathrm{Li}^{+}$extraction/insertion reversibly occurs between trirutile $\mathrm{Li}_{0.5} \mathrm{FeF}_{3}$ and Tetragonal $\mathrm{I} \mathrm{Li}_{0.5-x} \mathrm{FeF}_{3}$ through a singlephase reaction and a two-phase reaction around $4.0 \mathrm{~V}$, attaining a discharge capacity corresponding to $x=0.39$. This process is constrained at $25{ }^{\circ} \mathrm{C}$ but is stable over 20 cycles at $90{ }^{\circ} \mathrm{C}$. The side reaction that occurs from the residual $\mathrm{LiF}$ and $\mathrm{FeF}_{2}$ during the initial charge and discharge of $3.2-4.3 \mathrm{~V}$ is described in Figure S12 (Supporting Information).

Extending the lower cut-off voltage to $2.5 \mathrm{~V}$ triggers the conversion reaction from trirutile $\mathrm{Li}_{0.5} \mathrm{FeF}_{3}$ to a mixture of rutile $\mathrm{FeF}_{2}$ and $\mathrm{LiF}$ without forming another intermediate phase, which presumably results from the absence of $\mathrm{Li}^{+}$-accessible sites in the trirutile structure. During the second charging process, the sloping region starting from $3.1 \mathrm{~V}$ may be related to the reconstruction of the trirutile structure considering the corresponding plateau formed during the discharge process. However, this reaction seems to be incomplete and is followed by a short plateau at $4.1 \mathrm{~V}$ representing a two-phase reaction. According to the XRD analysis, this two-phase reaction leads to the formation of the Tetragonal II phase with a Li-Fe disordering trirutile structure. These observations suggest the poor recovery of the trirutile $\mathrm{Li}_{0.5} \mathrm{FeF}_{3}$ from the completely destructed state after the conversion reaction to $\mathrm{LiF}$ and $\mathrm{FeF}_{2}$. The second charge capacity is $159.5 \mathrm{mAh} \mathrm{g}^{-1}$ (Figure 2 (c)), corresponding to less $\mathrm{Li}^{+}$extraction $\left(x \sim 0.35\right.$ for $\left.\mathrm{Li}_{0.5-x} \mathrm{FeF}_{3}\right)$ compared to the first charge capacity $\left(x \sim 0.39\right.$ for $\left.\mathrm{Li}_{0.5-x} \mathrm{FeF}_{3}\right)$ thus providing 
evidence of the lower delithiated state after the second charge process. Previous publications have described the formation of trirutile $\mathrm{Li}_{0.5} \mathrm{FeF}_{3}$ as an intermediate obtained by inserting $\mathrm{Li}^{+}$ into a $\mathrm{FeF}_{3}$ framework with a distorted rhenium trioxide structure $(R-3 \mathrm{c}){ }^{26,}{ }^{27}$ However, there is no sign of rhombohedral $\mathrm{FeF}_{3}(R-3 \mathrm{c})$ after the second charge to $4.3 \mathrm{~V}$, contrary to other reports that confirmed the reconversion from $\mathrm{LiF}_{\mathrm{FeF}}$ to $\mathrm{FeF}_{3} .{ }^{68,75,87}$ Such a difference indicates that the starting material strongly affects the phase evolution of the Li-Fe-F systems. In the overall conversion chemistry of $\mathrm{FeF}_{3}$ at room temperature, the role of trirutile $\mathrm{Li}_{0.5} \mathrm{FeF}_{3}$ is considered to be limited because its electrochemical activity is extremely low. The difficulty of reconversion during charging also indicates little contribution of $\mathrm{Li}_{0.5} \mathrm{FeF}_{3}$ once it is converted to $\mathrm{LiF}$ and $\mathrm{FeF}_{2}$ during the first discharging.

\section{CONCLUSIONS}

Although the electrochemical behavior of $\mathrm{Li}_{0.5} \mathrm{FeF}_{3}$ with a trirutile structure has been long-pursued in literature, a functional charge-discharge mechanism has not been reported. In this study, the charge-discharge properties of trirutile $\mathrm{Li}_{0.5} \mathrm{FeF}_{3}$ were investigated at intermediate-temperatures operation that facilitates various processes in batteries. The trirutile $\mathrm{Li}_{0.5} \mathrm{FeF}_{3}$ was prepared by high-energy ball milling combined with heat treatment. Its electrochemical properties in the Li[FSA]$\left[\mathrm{C}_{2} \mathrm{C}_{1} \mathrm{im}\right][\mathrm{FSA}] \mathrm{IL}$ electrolyte were tested at $90{ }^{\circ} \mathrm{C}$ as the roomtemperature performance was very limited. At a rate of $0.2 \mathrm{C}(1$

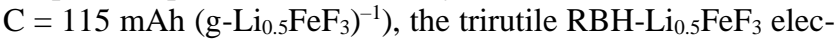
trode exhibits a reversible capacity of $89.8 \mathrm{mAh}\left(\mathrm{g}-\mathrm{Li}_{0.5} \mathrm{FeF}_{3}\right)^{-1}$ in the cut-off voltage of 3.2-4.3 V, corresponding to the reversible extraction and insertion of $0.39 \mathrm{Li}^{+}$. After 20 consecutive cycles, this reversible capacity slightly decreases to $85.7 \mathrm{mAh}$ $\left(\mathrm{g}-\mathrm{Li}_{0.5} \mathrm{FeF}_{3}\right)^{-1}$, delivering capacity retention of $95.4 \%$. Extension of the lower cut-off voltage to $2.5 \mathrm{~V}$ triggers another electrochemical reaction, giving an initial discharge capacity of $174.5 \mathrm{mAh}\left(\mathrm{g}-\mathrm{Li}_{0.5} \mathrm{FeF}_{3}\right)^{-1}$. Over 20 cycles, this value fades to $142.3 \mathrm{mAh}\left(\mathrm{g}-\mathrm{Li}_{0.5} \mathrm{FeF}_{3}\right)^{-1}$, leading to a capacity retention of $81.5 \%$. Additional GITT tests and synchrotron XRD analyses revealed the reversibility of topotactic $\mathrm{Li}^{+}$extraction/insertion in the voltage region of $3.2-4.3 \mathrm{~V}$ through a two-phase mode between the trirutile phase and Tetragonal I phase. Further lithiation at the lower voltage of $2.5 \mathrm{~V}$ gives rise to a conversion reaction to $\mathrm{LiF}$ and rutile $\mathrm{FeF}_{2}$. During the second charge from $2.5 \mathrm{~V}$, reconversion from $\mathrm{LiF}$ and $\mathrm{FeF}_{2}$ resulted in the $\mathrm{Li} / \mathrm{Fe}$ disordered trirutile phase with low crystallinity instead of the ordered trirutile $\mathrm{Li}_{0.5} \mathrm{FeF}_{3}$ or rhombohedral $\mathrm{FeF}_{3}$, indicating the ordered trirutile phase did not recover after undergoing the conversion process.

This work provides comprehensive insights into the overall reaction mechanisms of trirutile $\mathrm{Li}_{0.5} \mathrm{FeF}_{3}$ as a positive electrode for $\mathrm{Li}$-ion batteries to expand the information space of the Li$\mathrm{Fe}-\mathrm{F}$ system phase transformation. It also proposes new ideas for developing high energy-density lithium-ion batteries based on the reversible topotactic reactions of the trirutile structural framework. Further modification of the trirutile materials with different transition metals or fabrication techniques is expected to extend their practical use, including operation at room temperature. Synthesis of completely pure trirutile $\mathrm{Li}_{0.5} \mathrm{FeF}_{3}$ was not achieved by high-energy ball milling and heat treatment in this study, as residual amounts of $\mathrm{FeF}_{2}$ and $\mathrm{LiF}$ were found throughout the process. As such, improvement in the synthetic procedure will be in the scope of future studies.

\section{ASSOCIATED CONTENT}

\section{Supporting Information}

The Supporting Information is available free of charge on the ACS Publications website. Additional structural and morphological information, electrochemical properties and the side reaction pathway.

\section{AUTHOR INFORMATION}

\author{
Corresponding Author \\ *Email: k-matsumoto@energy.kyoto-u.ac.jp
}

Author Contributions

All authors have given approval to the final version of the manuscript.

\section{ACKNOWLEDGMENT}

This study was partly supported by Japan Society for the Promotion of Science (JSPS, KAKENHI Grant Number 19H02811). One of the coauthors, Y. Z., thanks the China Scholarship Council (CSC) for the financial support.

\section{REFERENCES}

(1) Demirocak, D.; Srinivasan, S.; Stefanakos, E. A Review on Nanocomposite Materials for Rechargeable Li-ion Batteries. Appl. Sci. 2017, 7, 731

(2) Li, M.; Lu, J.; Chen, Z.; Amine, K. 30 Years of Lithium-Ion Batteries. Adv. Mater. 2018, 30, 1800561.

(3) Winter, M.; Barnett, B.; Xu, K. Before Li Ion Batteries. Chem. Rev. 2018, 118, 11433-11456.

(4) Shukla, A.; Venugopalan, S.; Hariprakash, B. Nickel-Based Rechargeable Batteries. J. Power Sources 2001, 100, 125-148.

(5) Taniguchi, A.; Fujioka, N.; Ikoma, M.; Ohta, A. Development of Nickel/Metal-Hydride Batteries for EVs and HEVs. J. Power Sources 2001, 100, 117-124.

(6) Doerffel, D.; Sharkh, S. A Critical Review of Using the Peukert Equation for Determining the Remaining Capacity of LeadAcid and Lithium-Ion Batteries. J. Power Sources 2006, 155, 395-400.

(7) Mizushima, K.; Jones, P.; Wiseman, P.; Goodenough, J. $\mathrm{Li}_{\mathrm{x}} \mathrm{CoO}_{2}(0<\mathrm{x} \leq 1)$ : A New Cathode Material for Batteries of High Energy Density. Solid State Ion. 1981, 15, 783-789.

(8) Pan, C.; Banks, C.; Song, W.; Wang, C.; Chen, Q.; Ji, X. Recent Development of $\mathrm{LiNi}_{\mathrm{x}} \mathrm{Co}_{\mathrm{y}} \mathrm{Mn}_{\mathrm{z}} \mathrm{O}_{2}$ : Impact of Micro/Nano Structures for Imparting Improvements in Lithium Batteries. Trans. Nonferrous Met. Soc. China 2013, 23, 108-119.

(9) Liu, Q.; He, H.; Li, Z.; Liu, Y.; Ren, Y.; Lu, W.; Lu, J.; Stach, E.; Xie, J. Rate-Dependent, Li-Ion Insertion/Deinsertion Behavior of $\mathrm{LiFePO}_{4}$ Cathodes in Commercial $18650 \mathrm{LiFePO}_{4}$ Cells. ACS Appl. Mater. Interfaces 2014, 6, 3282-3289.

(10) Martha, S.; Nanda, J.; Zhou, H.; Idrobo, J.; Dudney, N.; Pannala, S.; Dai, S.; Wang, J.; Braun, P. Electrode Architectures for High Capacity Multivalent Conversion Compounds: Iron (ii and iii) Fluoride. RSC Adv. 2014, 4, 6730-6737.

(11) Li, C.; Chen, K.; Zhou, X.; Maier, J. Electrochemically Driven Conversion Reaction in Fluoride Electrodes for Energy Storage Devices. npj Comput. Mater. 2018, 4, 1-15.

(12) Li, H.; Richter, G.; Maier, J. Reversible Formation and Decomposition of LiF Clusters Using Transition Metal Fluorides as Precursors and Their Application in Rechargeable Li Batteries. Adv. Mater. 2003, 15, 736-739.

(13) Li, H.; Balaya, P.; Maier, J. Li-Storage via Heterogeneous Reaction in Selected Binary Metal Fluorides and Oxides. J. Electrochem. Soc. 2004, 151, A1878-A1885.

(14) Zhou, M.; Zhao, L.; Kitajou, A.; Okada, S.; Yamaki, J. Mechanism on Exothermic Heat of $\mathrm{FeF}_{3}$ Cathode in Li-Ion Batteries. $J$. Power Sources 2012, 203, 103-108.

(15) Kitajou, A.; Eguchi, K.; Ishado, Y.; Setoyama, H.; Okajima, T.; Okada, S. Electrochemical Properties of Titanium Fluoride with 
High Rate Capability for Lithium-Ion Batteries. J. Power Sources 2019, $419,1-5$.

(16) Conte, D.; Pinna, N. A Review on the Application of Iron(III) Fluorides as Positive Electrodes for Secondary Cells. Mater. Renew. Sustain. Energy 2014, 3, 1-22.

(17) Zhang, N.; Xiao, X.; Pang, H. Transition Metal (Fe, Co, Ni) Fluoride-Based Materials for Electrochemical Energy Storage. $\mathrm{Na}$ noscale Horiz. 2019, 4, 99-116.

(18) Li, R.; Wu, S.; Yang, Y.; Zhu, Z. Structural and Electronic Properties of Li-Ion Battery Cathode Material $\mathrm{FeF}_{3}$. J. Phys. Chem. C 2010, 114, 16813-16817.

(19) Li, L.; Meng, F.; Jin, S. High-Capacity Lithium-Ion Battery Conversion Cathodes Based on Iron Fluoride Nanowires and Insights into the Conversion Mechanism. Nano Lett. 2012, 12, 6030-6037.

(20) Liu, P.; Vajo, J.; Wang, J.; Li, W.; Liu, J. Thermodynamics and Kinetics of the $\mathrm{Li} / \mathrm{FeF}_{3}$ Reaction by Electrochemical Analysis. $J$. Phys. Chem. C 2012, 116, 6467-6473.

(21) Tan, H.; Smith, H.; Kim, L.; Harding, T.; Jones, S.; Fultz, B. Electrochemical Cycling and Lithium Insertion in Nanostructured $\mathrm{FeF}_{3}$ Cathodes. J. Electrochem. Soc. 2014, 161, A445-A449.

(22) Kitajou, A.; Tanaka, I.; Tanaka, Y.; Kobayashi, E.; Setoyama, H.; Okajima, T.; Okada, S. Discharge and Charge Reaction of Perovskite-type $\mathrm{MF}_{3}(\mathrm{M}=\mathrm{Fe}$ and $\mathrm{Ti})$ Cathodes for Lithium-Ion Batteries. Electrochemistry 2017, 85, 472-477.

(23) Badway, F.; Cosandey, F.; Pereira, N.; Amatucci, G. Carbon Metal Fluoride Nanocomposites High-Capacity Reversible Metal Fluoride Conversion Materials as Rechargeable Positive Electrodes for $\mathrm{Li}$ Batteries. J. Electrochem. Soc. 2003, 150, A1318-A1327.

(24) Badway, F.; Pereira, N.; Cosandey, F.; Amatuccia, G. Carbon-Metal Fluoride Nanocomposites Structure and Electrochemistry of $\mathrm{FeF}_{3}$ :C. J. Electrochem. Soc. 2003, 150, A1209-A1218.

(25) Doe, R.; Persson, K.; Meng, Y.; Ceder, G. First-Principles Investigation of the Li-Fe-F Phase Diagram and Equilibrium and Nonequilibrium Conversion Reactions of Iron Fluorides with Lithium. Chem. Mater. 2008, 20, 5274-5283.

(26) Yamakawa, N.; Jiang, M.; Key, B.; Grey, C. Identifying the Local Structures Formed during Lithiation of the Conversion Material, Iron Fluoride, in a Li Ion Battery: A Solid-State NMR, X-ray Diffraction, and Pair Distribution Function Analysis Study. J. Am. Chem. Soc. 2009, 131, 10525-10536.

(27) Li, L.; Jacobs, R.; Gao, P.; Gan, L.; Wang, F.; Morgan, D.; Jin, S. Origins of Large Voltage Hysteresis in High-Energy-Density Metal Fluoride Lithium-Ion Battery Conversion Electrodes. J. Am. Chem. Soc. 2016, 138, 2838-2848.

(28) Shachar, G.; Makovsky, J.; Shaked, H. Neutron-Diffraction Study of the Magnetic Structure of the Trirutile $\mathrm{LiFe}_{2} \mathrm{~F}_{6}$. Phys. Rev. B 1972, 6, 1968-1974.

(29) Fourquet, J.; Samedi, E.; Calage, Y. Le Trirutile Ordonné $\mathrm{LiFe}_{2} \mathrm{~F}_{6}$ : Croissance Cristalline et étude Structurale. J. Solid State Chem. 1988, 77, 84-89.

(30) Martin, A.; Doublet, M.; Kemnitz, E.; Pinna, N. Reversible Sodium and Lithium Insertion in Iron Fluoride Perovskites. Adv. Funct. Mater. 2018, 28, 1802057.

(31) Viebahn, W.; Rudorff, W.; Kornelson, H. Fluor-Trirutile $\mathrm{LiMe}^{\mathrm{II}} \mathrm{Me}^{\mathrm{III}} \mathrm{F}_{6}$ und zwei neue Sauerstoflf-Trirutile LiMe $\mathrm{Me}^{\mathrm{VI}} \mathrm{O}_{6} . Z$. Naturforsch. B 1967, 22, 1218.

(32) Viebahn, W.; Rudorff, W.; Viebahn-Hänsler, R. Untersuchungen an Ternären und Quaternären Fluoriden III: Fluortrirutile und weitere Lithiumhexafluorometallate, LiMe ${ }^{\mathrm{II}} \mathrm{Me}^{\mathrm{III}} \mathrm{F}_{6}$. Sauerländer 1969, 23, 503-510.

(33) Portier, J.; Tressaud, A.; Pape, R.; Hagenmuller, P. CHIMIE MINERALE. Étude Cristallographique at Magnétique d'un Fluorure inédit de Type Trirutile. C. R. Acad. Sci. (Paris), Serie C 1968, 267, 1711-1713.

(34) Greenwood, N.; Howe, A.; Menil, F. Mössbauer Studies of Order and Disorder in Rutile and Trirutile Compounds derived from $\mathrm{FeF}_{2}$. J. Chem. Soc. A 1971, 2218-2224.

(35) Wintenberger, M. Determination de la Structure Magnetique de $\mathrm{LiFe}_{2} \mathrm{~F}_{6}$ par Diffraction Neutronique. Solid State Commun. 1972, 10 , 739-744.
(36) Liao, P.; Li, J.; Dahn, J. Lithium Intercalation in $\mathrm{LiFe}_{2} \mathrm{~F}_{6}$ and $\mathrm{LiMgFeF}_{6}$ Disordered Trirutile-Type Phases. J. Electrochem. Soc. 2010, 157, A355-A361.

(37) Liao, P.; Dunlap, R.; Dahn, J. In Situ Mössbauer Effect Study of Lithium Intercalation in $\mathrm{LiFe}_{2} \mathrm{~F}_{6}$. J. Electrochem. Soc. 2010, 157, A1080-A1084.

(38) Zheng, Y.; Li, R.; Wu, S.; Wen, Y.; Zhu, Z.; Yang, Y. FirstPrinciples Investigation on the Lithium Ion Insertion/Extraction in Trirutile $\mathrm{Li}_{x} \mathrm{FeF}_{3}$, Electrochemistry 2013, 81, 12-15.

(39) Lin, L.; Xu, Q.; Zhang, Y.; Zhang, J.; Liang, Y.; Dong, S. Ferroelectric Ferrimagnetic $\mathrm{LiFe}_{2} \mathrm{~F}_{6}$ : Charge-Ordering-Mediated Magnetoelectricity. Phys. Rev. Mater. 2017, 1, 1-8.

(40) Mori, M.; Tanaka, S.; Senoh, H.; Matsui, K.; Okumura, T.; Sakaebe, H.; Kiuchi, H.; Matsubara, E. First-Principles Calculations of the Atomic Structure and Electronic States of $\mathrm{Li}_{x} \mathrm{FeF}_{3}$. Phys. Rev. B 2019, $100,035128$.

(41) Hwang, J.; Matsumoto, K.; Hagiwara, R. $\mathrm{Na}_{3} \mathrm{~V}_{2}\left(\mathrm{PO}_{4}\right)_{3} / \mathrm{C}$ Positive Electrodes with High Energy and Power Densities for Sodium Secondary Batteries with Ionic Liquid Electrolytes That Operate across Wide Temperature Ranges. Adv. Sustain. Syst. 2018, 2, 1700171.

(42) Matsumoto, K.; Hwang, J.; Kaushik, S.; Chen, C.; Hagiwara, R. Advances in Sodium Secondary Batteries Utilizing Ionic Liquid Electrolytes. Energy Environ. Sci. 2019, 12, 3247-3287.

(43) Lin, X.; Salari, M.; Arava, L.; Ajayan, P.; Grinstaff, M. High Temperature Electrical Energy Storage: Advances, Challenges, and Frontiers. Chem. Soc. Rev. 2016, 45, 5848-5887.

(44) Rodrigues, M.-T.; Babu, G.; Gullapalli, H.; Kalaga, K.; Sayed, F.; Kato, K.; Joyner, J.; Ajayan, P. A Materials Perspective on Li-ion Batteries at Extreme Temperatures. Nat. Energy 2017, 2, 17108.

(45) Guidotti, R.; Reinhardt, F.; Odinek, J. Overview of HighTemperature Batteries for Geothermal and Oil/Gas Borehole Power Sources. J. Power Sources 2004, 136, 257-262.

(46) Lewandowski, A.; Świderska-Mocek, A. Ionic Liquids as Electrolytes for Li-ion Batteries-An Overview of Electrochemical Studies. J. Power Sources 2009, 194, 601-609.

(47) Armand, M.; Endres, F.; MacFarlane, D.; Ohno, H.; Scrosati, B. Ionic-Liquid Materials for the Electrochemical Challenges of the Future. Nat. Mater. 2009, 8, 621-629.

(48) MacFarlane, D.; Tachikawa, N.; Forsyth, M.; Pringle, J.; Howlett, P.; Elliott, G.; Davis, J.; Watanabe, M.; Simon, P.; Angell, C. Energy Applications of Ionic Liquids. Energy Environ. Sci. 2014, 7, $232-250$

(49) MacFarlane, D.; Forsyth, M.; Howlett, P.; Kar, M.; Passerini, S.; Pringle, J.; Ohno, H.; Watanabe, M.; Yan, F.; Zheng, W.; Zhang, S.; Zhang, J. Ionic Liquids and Their Solid-state Analogues as Materials for Energy Generation and Storage. Nat. Rev. Mater. 2016, 1, 15005.

(50) Watanabe, M.; Thomas, M.; Zhang, S.; Ueno, K.; Yasuda, T.; Dokko, K. Application of Ionic Liquids to Energy Storage and Conversion Materials and Devices. Chem. Rev. 2017, 117, 7190-7239.

(51) Yang, Q.; Zhang, Z.; Sun, X.; Hu, Y.; Xing, H.; Dai, S. Ionic Liquids and Derived Materials for Lithium and Sodium Batteries. Chem. Soc. Rev. 2018, 47, 2020-2064.

(52) Basile, A.; Hilder, M.; Makhlooghiazad, F.; Pozo-Gonzalo, C.; MacFarlane, D.; Howlett, P.; Forsyth, M. Ionic Liquids and Organic Ionic Plastic Crystals: Advanced Electrolytes for Safer High Performance Sodium Energy Storage Technologies. Adv. Energy Mater. 2018, 8,1703491

(53) Torimoto, T.; Tsuda, T.; Okazaki, K.; Kuwabata, S. New Frontiers in Materials Science Opened by Ionic Liquids. Adv. Mater. 2010, 22, 1196-1221.

(54) Ishikawa, M.; Sugimoto, T.; Kikuta, M.; Ishiko, E.; Kono, M. Pure Ionic Liquid Electrolytes Compatible with A Graphitized Carbon Negative Electrode in Rechargeable Lithium-Ion Batteries. $J$. Power Sources 2006, 162, 658-662.

(55) Matsumoto, H.; Sakaebe, H.; Tatsumi, K.; Kikuta, M.; Ishiko, E.; Kono, M. Fast Cycling of $\mathrm{Li} / \mathrm{LiCoO}_{2}$ Cell with Low-Viscosity Ionic Liquids Based on bis(fluorosulfonyl)imide [FSI]-. J. Power Sources 2006, 160, 1308-1313.

(56) Shkrob, I.; Marin, T.; Zhu, Y.; Abraham, D. Why Bis(fluorosulfonyl)imide Is a "Magic Anion" for Electrochemistry. $J$. Phys. Chem. C 2014, 118, 19661-19671. 
(57) Zhang, H.; Feng, W.; Nie, J.; Zhou, Z. Recent Progresses on Electrolytes of Fluorosulfonimide Anions for Improving the Performances of Rechargeable Li and Li-Ion Battery. J. Fluorine Chem. 2015, $174,49-61$.

(58) Matsumoto, K.; Nishiwaki, E.; Hosokawa, T.; Tawa, S.; Nohira, T.; Hagiwara, R. Thermal, Physical, and Electrochemical Properties of $\mathrm{Li}\left[\mathrm{N}\left(\mathrm{SO}_{2} \mathrm{~F}\right)_{2}\right]$-[1-Ethyl-3-methylimidazolium] $\left[\mathrm{N}\left(\mathrm{SO}_{2} \mathrm{~F}\right)_{2}\right]$ Ionic Liquid Electrolytes for Li Secondary Batteries Operated at Room and Intermediate Temperatures. J. Phys. Chem. C 2017, 121, 9209-9219.

(59) Hwang, J.; Okada, H.; Haraguchi, R.; Tawa, S.; Matsumoto, K.; Hagiwara, R. Ionic Liquid Electrolyte for Room to Intermediate Temperature Operating Li Metal Batteries: Dendrite Suppression and Improved Performance. J. Power Sources 2020, 453, 227911.

(60) Guerfi, A.; Duchesne, S.; Kobayashi, Y.; Vijh, A.; Zaghib, K. $\mathrm{LiFePO}_{4}$ and Graphite Electrodes with Ionic Liquids Based on bis(fluorosulfonyl)imide (FSI) - for Li-ion Batteries. J. Power Sources 2008, 175, 866-873.

(61) Yamagata, M.; Matsui, Y.; Sugimoto, T.; Kikuta, M.; Higashizaki, T.; Kono, M.; Ishikawa, M. High-Performance Graphite Negative Electrode in A bis(fluorosulfonyl)imide-Based Ionic Liquid. J. Power Sources 2013, 227, 60-64.

(62) Toby, B. EXPGUI, A Graphical User Interface for GSAS. $J$. Appl. Cryst. 2001, 34, 210-213.

(63) Rodríguez-Carvajal, J.; Roisnel, T. Line Broadening Analysis Using FULLPROF*: Determination of Microstructural Properties. Mater. Sci. Forum 2004, 443-444, 123-126.

(64) Momma, K.; Izumi, F. VESTA: A Three-Dimensional Visualization System for Electronic and Structural Analysis. J. Appl. Crystallogr. 2008, 41, 653-658.

(65) Kinast, E.; Zawislak, L.; da Cunha, J.; Antonietti, V.; de Vasconcellos, M.; dos Santos, C. Coexistence of Rutile and Trirutile Phases in a Natural Tapiolite Sample. J. Solid State Chem. 2002, 163, $218-223$.

(66) Nishijima, M.; Gocheva, I. D.; Okada, S.; Doi, T.; Yamaki, J.; Nishida, T. Cathode Properties of Metal Trifluorides in Li and $\mathrm{Na}$ Secondary Batteries. J. Power Sources 2009, 190, 558-562.

(67) Yabuuchi, N.; Sugano, M.; Yamakawa, Y.; Nakai, I.; Sakamoto, K.; Muramatsu, H.; Komaba, S. Effect of Heat-Treatment Process on $\mathrm{FeF}_{3}$ Nanocomposite Electrodes for Rechargeable Li Batteries. J. Mater. Chem. 2011, 21, 10035.

(68) Tawa, S.; Sato, Y.; Orikasa, Y.; Matsumoto, K.; Hagiwara, R. Lithium Fluoride/Iron Difluoride Composite Prepared by a Fluorolytic Sol-Gel Method: Its Electrochemical Behavior and Charge-Discharge Mechanism as a Cathode Material for Lithium Secondary Batteries. J. Power Sources 2019, 412, 180-188.

(69) Fan, X.; Hu, E.; Ji, X.; Zhu, Y.; Han, F.; Hwang, S.; Liu, J.; Bak, S.; Ma, Z.; Gao, T.; Liou, S.; Bai, J.; Yang, X.; Mo, Y.; Xu, K.; Su, D.; Wang, C. High Energy-Density and Reversibility of Iron Fluoride Cathode Enabled via An Intercalation-Extrusion Reaction. Nat. Commun. 2018, 9, 2324.

(70) Han, Y.; Li, H.; Li, J.; Si, H.; Zhu, W.; Qiu, X. Hierarchical Mesoporous Iron Fluoride with Superior Rate Performance for Lithium-Ion Batteries. ACS Appl. Mater. Interfaces 2016, 8, 32869-32874.

(71) Jiang, M.; Wang, X.; Hu, H.; Wei, S.; Fu, Y.; Shen, Y. In Situ Growth and Performance of Spherical $\mathrm{Fe}_{2} \mathrm{~F}_{5} \cdot \mathrm{H}_{2} \mathrm{O}$ Nanoparticles in Multi-Walled Carbon Nanotube Network Matrix as Cathode Material for Sodium Ion Batteries. J. Power Sources 2016, 316, 170-175.
(72) Kim, S.; Seo, D.; Gwon, H.; Kim, J.; Kang, K. Fabrication of $\mathrm{FeF}_{3}$ Nanoflowers on CNT Branches and their Application to High Power Lithium Rechargeable Batteries. Adv. Mater. 2010, 22, $5260-5264$

(73) Kang, W.; Li, F.; Zhao, Y.; Qiao, C.; Ju, J.; Cheng, B. Fabrication of Porous $\mathrm{Fe}_{2} \mathrm{O}_{3} /$ PTFE Nanofiber Membranes and their Application as A Catalyst for Dye Degradation. RSC Adv. 2016, 6, 32646-32652.

(74) Kim, M.; Lee, S.; Kang, B. Fast-Rate Capable Electrode Material with Higher Energy Density than $\mathrm{LiFePO}_{4}$ : $4.2 \mathrm{~V} \mathrm{LiVPO}_{4} \mathrm{~F}$ Synthesized by Scalable Single-Step Solid-State Reaction. Adv. Sci. 2016, 3, 1500366

(75) Kim, S.; Nam, K.; Seo, D.; Hong, J.; Kim, H.; Gwon, H.; Kang, K. Energy Storage in Composites of A Redox Couple Host and A Lithium Ion Host. Nano Today 2012, 7, 168-173.

(76) Reimers, J.; Dahn, J. Electrochemical and In Situ X-Ray Diffraction Studies of Lithium Intercalation in $\mathrm{Li}_{x} \mathrm{CoO}_{2}$. J. Electrochem. Soc. 1992, 139, 2091-2097.

(77) Koerver, R.; Zhang, W.; de Biasi, L.; Schweidler, S.; Kondrakov, A.; Kolling, S.; Brezesinski, T.; Hartmann, P.; Zeier, W.; Janek, J. Chemo-Mechanical Expansion of Lithium Electrode Materials - on the Route to Mechanically Optimized All-Solid-State Batteries. Energy Environ. Sci. 2018, 11, 2142-2158.

(78) Kanamura, T.; Naito, H.; Yao, T.; Takehara, Z. Structural Change of the $\mathrm{LiMn}_{2} \mathrm{O}_{4}$ Spinel Structure Induced by Extraction of Lithium. J. Muter. Chem. 1996, 6, 33-36.

(79) Asadi, A.; Aghamiri, S.; Talaie, M. Molecular Dynamics Simulation of $\mathrm{A} \mathrm{Li}_{\mathrm{x}} \mathrm{Mn}_{2} \mathrm{O}_{4}$ Spinel Cathode Material in Li-ion Batteries. RSC Advances 2016, 6, 115354-115363.

(80) Gibot, P.; Casas-Cabanas, M.; Laffont, L.; Levasseur, S.; Carlach, P.; Hamelet, S.; Tarascon, J. M.; Masquelier, C. Room-Temperature Single-Phase Li Insertion/Extraction in Nanoscale $\mathrm{Li}_{x} \mathrm{FePO}_{4}$ Nat. Mater. 2008, 7, 741-747.

(81) Ramana, C.; Mauger, A.; Gendron, F.; Julien, C.; Zaghib, K. Study of the Li-Insertion/Extraction Process in $\mathrm{LiFePO}_{4} / \mathrm{FePO}_{4} . J$. Power Sources 2009, 187, 555-564.

(82) Srivastava, U.; Nigam, H. X-Ray Absorption Edge Spectrometry (XAES) as Applied to Coordination Chemistry. Coordin. Chem. Rev. 1972, 9, 275-310.

(83) Parsai, N.; Mishra, A. Study of XAFS of some Fe Compounds and Determination of First Shell Radial Distance. J. Phys. Conf. Ser. 2017, 836, 012045.

(84) Yamamoto, T. Assignment of Pre-Edge Peaks in K-edge Xray Absorption Spectra of 3D Transition Metal Compounds: Electric Dipole or Quadrupole? X-Ray Spectrom. 2008, 37, 572-584.

(85) Biasi, L.; Lieser, G.; Drager, C.; Indris, S.; Rana, J.; Schumacher, G.; Monig, R.; Ehrenbery, H.; Binder, J.; Gebwein, H. $\mathrm{LiCaFeF}_{6}$ : A Zero-Strain Cathode Material for Use in Li-Ion Batteries. J. Power Sources 2017, 362, 192-201.

(86) Hwang, I.; Jung, S.; Jeong, E.; Kim, H.; Cho, S.; Ku, K.; Kim, H.; Yoon, W.; Kang, K. NaF-FeF 2 Nanocomposite: New Type of Na-Ion Battery Cathode Material. Nano Res. 2017, 10, 4388-4397.

(87) Tawa, S.; Matsumoto, K.; Hagiwara, R. Reaction Pathways of Iron Trifluoride Investigated by Operation at $363 \mathrm{~K}$ Using an Ionic Liquid Electrolyte. J. Electrochem.Soc. 2019, 166, A2105-A2110. 
TOC graphic
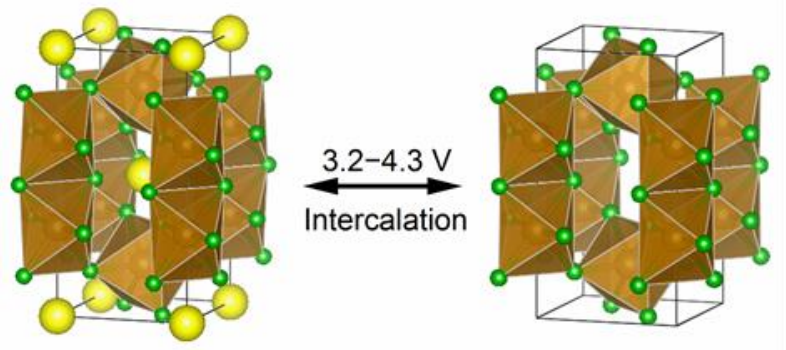

Trirutile phase

Tetragonal I 